\title{
Adaptive multistep model predictive control for tubular grid-connected solid oxide fuel cells
}

\author{
Linfei Yin ${ }^{\mathrm{a}, *}$, Dongduan Liu ${ }^{\mathrm{a}}$, Mingshan Mo ${ }^{\mathrm{a}}$ \\ ${ }^{a}$ College of Electrical Engineering, Guangxi University, Nanning, Guangxi, 530004, China \\ *Corresponding author;
}

Email: yinlinfei@163.com (L. Yin); gxdqliudongduan@163.com (D. Liu); mingshanmo@163.com(M. Mo) Abstract: In the research of renewable energy power generation, tubular grid-connected solid oxide fuel cells with the apparent advantage in voltage regulation have been widely applied in power systems. Recently, a model predictive control has been applied to consider the nonlinear constraints of tubular grid-connected solid oxide fuel cells, which cannot be considered by a proportional-integral-derivative controller. While both model predictive control and proportional-integral-derivative controller achieve only $80 \%$ fuel efficiency, which should be improved. An adaptive multistep model predictive control (AMMPC) is proposed to improve the fuel efficiency of tubular grid-connected solid oxide fuel cells and simultaneously consider systemic thermodynamics and electrochemistry constraints. The AMMPC contains the advantages of adaptive control and multistep model predictive control. Both adaptive two-step model predictive control and three-step model predictive control are designed for tubular grid-connected solid oxide fuel cells. With the more accurate prediction ability, the AMMPC improves the fuel efficiency of tubular grid-connected solid oxide fuel cells with higher fuel efficiency (86.5\%) than model predictive control (80\%) and proportional-integral-derivative (80\%). Both feasibility and effectiveness of the AMMPC are verified with high fuel efficiency under both simple and complex power demands cases.

Keywords: Adaptive multistep model predictive control; adaptive control; grid-connected solid oxide fuel cells

\section{Introduction}

Recently, renewable energy sources have been introduced to large-scale interconnected power systems for reducing frequency deviation and voltage deviation [1]. For example, tubular grid-connected solid oxide fuel cells (TGSOFCs) have been applied for the voltage regulation of power systems [2]. The combination of electrolytic hydrogen production and hydrogen storage might be an effective way to improve the efficiency of renewable sources [3]. As an auxiliary technology of renewable energy storage, the power system with TGSOFCs has been regarded as a candidate power supply for the voltage regulation of power systems [4]. The TGSOFC with high energy conversion efficiency, fast power response, and stable output voltage has been widely applied in industrial applications [5].

Fig. 1 shows the chemical reaction $\left(2 \mathrm{H}_{2}+2 \mathrm{O}^{2-}=2 \mathrm{H}_{2} \mathrm{O}+4 e^{-} ; \mathrm{O}_{2}+4 e^{-}=2 \mathrm{O}^{2-} ; 2 \mathrm{H}_{2}+\mathrm{O}_{2}=2 \mathrm{H}_{2} \mathrm{O}\right)$ and power transmission of a simplified TGSOFC (including an anode, cathode, voltage source inverter, transformer, load, power grid) [6]. Hydrogen is provided to the anode through the fuel processor; oxygen is supplied to the cathode through the air compressor. Individually, the chemical reaction occurs in the electrolyte and generates an electromotive force [6]. 


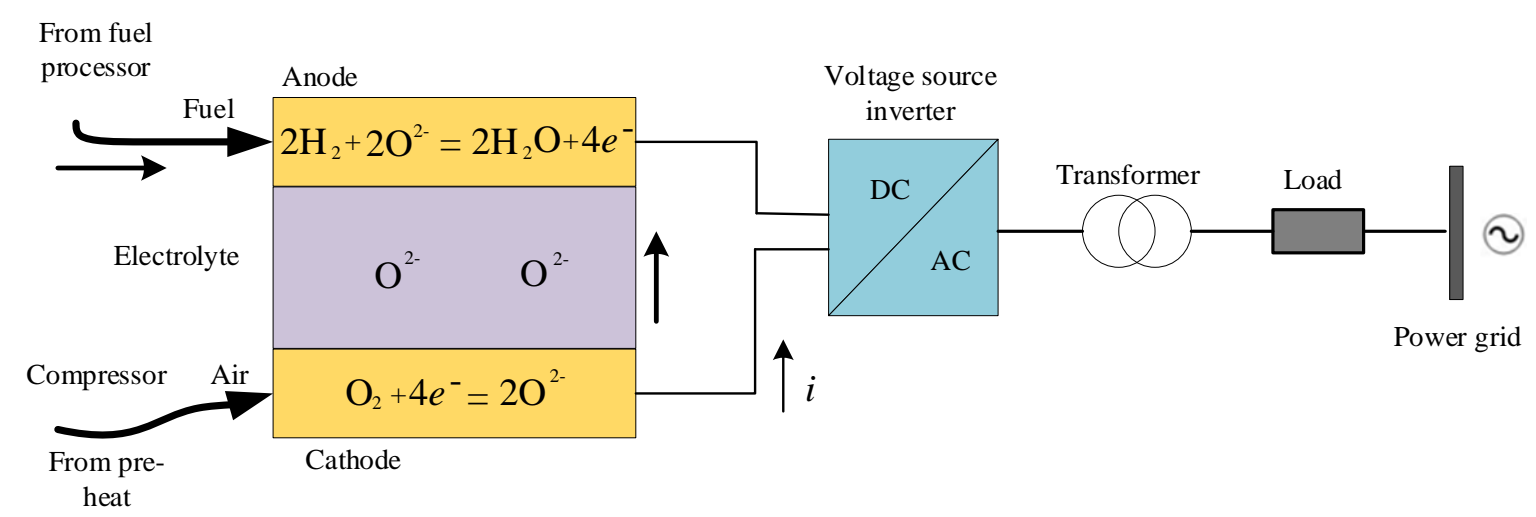

Fig. 1. Chemical reaction and power transmission of tubular grid-connected solid oxide fuel cells

The TGSOFCs has the following features: (i) TGSOFCs for peak shaving should rapidly respond to the demand sides of power systems [7]; (ii) the fuel efficiency of TGSOFCs should be configured as the maximum value as possible [8]; (iii) the control system of TGSOFCs is a real-time strongly nonlinear control system [9]. The power system with TGSOFCs has been optimized by a setpoint scheduler and a controlled tracking controller $[10,11]$. The nonlinear control system for the TGSOFCs is considered in this paper.

The fuel efficiency of TGSOFCs should be configured as much larger as possible to reduce the economic cost of fuel cells [12]. However, the fuel efficiency of TGSOFCs that larger than $90 \%$ lead to insufficient fuel for TGSOFCs [13]. The fuel efficiency should be effectively improved in the range from $70 \%$ to $90 \%$ when considering the safe operation and the economic cost of TGSOFCs [14]. An optimized proportional-integralderivative (PID) can only achieve a maximum of $80 \%$ fuel efficiency [15]. An intelligent controller should be designed to improve the fuel efficiency of TGSOFCs.

The model predictive control (MPC) has recently been applied to obtain high fuel efficiency of TGSOFCs than other control methods [16]. Besides, the MPC has been introduced to the tracking controller to improve the fuel efficiency of TGSOFCs $[17,18]$. The active disturbance rejection control and MPC have been combined with maintaining the fuel efficiency of TGSOFCs to an expected constant [19]. The PID could not be suitable for the constraints of the nonlinear TGSOFCs [20]. The maximum power point tracking algorithms could not effectively improve the fuel efficiency of the TGSOFC with nonlinear constraints [21]. To improve the fuel efficiency near to $90 \%$ and provide a control strategy for nonlinear dynamic systems, a more intelligent control method with more accurate prediction should be designed for TGSOFCs. This paper adopts an adaptive multistep model predictive control (AMMPC) for the tracking controller of TGSOFCs.

The AMMPC is proposed to improve the fuel efficiency of a TGSOFC. The AMMPC consists of adaptive control and multistep model predictive control. The AMMPC aims to control TGSOFCs with nonlinearities and constraint characteristics. The AMMPC consists of an adaptive control and multistep model predictive control. Besides, the AMMPC can simultaneously supply multiple output actions. Consequently, the significant contributions of the tracking controller based on the AMMPC for the TGSOFCs are listed as follows: (i) the adaptive control of AMMPC can control TGSOFCs with nonlinearity; (ii) the AMMPC shows the convenience and robustness for nonlinear system constraints; (iii) the AMMPC can gain a stable output voltage and higher fuel efficiency for TGSOFCs. 
The remaining works of this article are arranged as follows. The TGSOFC is introduced in Section 2. The control structure of the AMMPC and fuel system protection control are established in Section 3. The AMMPC with higher fuel efficiency and better tracking performances are represented as Section 4. Conclusions are briefly listed as Section 5.

\section{Tubular grid-connected solid oxide fuel cell models}

The principle of TGSOFCs is shown in following subsection.

\subsection{Framework of tubular grid-connected solid oxide fuel cell models}

TGSOFCs have higher airtightness and structural integrity than other types of GSOFC. A TGSOFC includes a cathode, an electrolyte, and an anode (Fig. 2). The air (oxidant) participates in the reduction reaction of TGSOFC; the airflow is supplied to the anode through the air supply tube; then, airflow traverses the circular channel of the cathode inversely. The fuel flow participates in oxidation reaction in the cathode of TGSOFC. The fuel flow is then supplied to the inlet of TGSOFC through the air supply tube. Then, the electrolyte is clipped between the cathode and the anode of the TGSOFC. An electrochemical reaction occurs in the electrolyte of the TGSOFC.

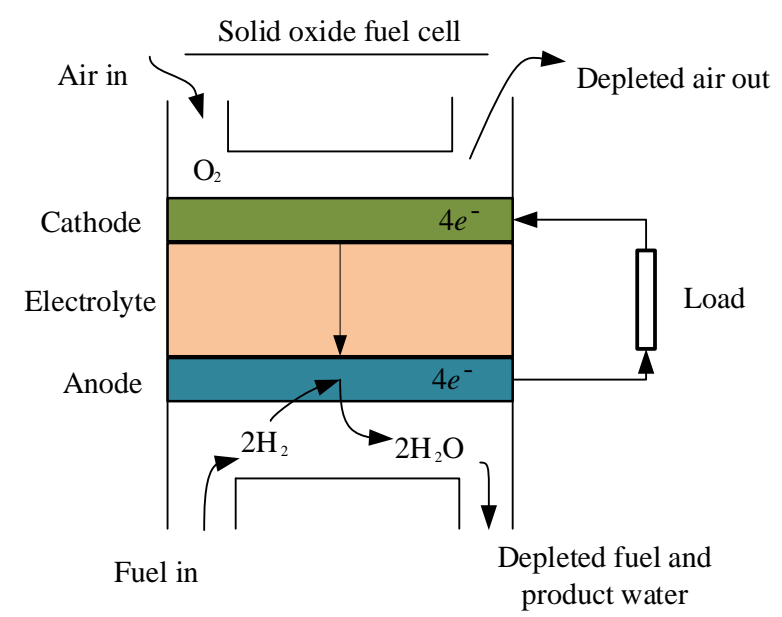

Fig. 2. Sectional chart of a tubular solid oxide fuel cell

Since the initial preheating process of TGSOFCs is not high [22], the preheating process can significantly influence its long-term dynamics [23]. Thus, the thermal characteristics of the fuel cell model should be considered. The internal resistance of TGSOFCs increases with the increasing process of the temperature of TGSOFCs and the voltage output would be affected. Based on the comprehensive study of the thermal characteristics of TGSOFCs, Wang and Nehrir proposed a new fuel cell model, which considers the electrochemical and thermal characteristics of TGSOFCs [24]. The TGSOFCs, which have enough accuracy and reasonable complexity, are suitable for modern power systems [24].

\subsection{Mass conservation of tubular grid-connected solid oxide fuel cells}

Assume that: a TGSOFC adopts one-dimensional analysis processing; the stoichiometric proportion of cathode air is larger than that of the anode fuel; the pressure of the air and hydrogen of the TGSOFC is equal everywhere in the air supply tube. Then, the dynamic TGSOFC model and the analysis methods have been built [23]. The pressure of hydrogen with Faraday Law is described as [25], 


$$
p_{\mathrm{H}_{2}}^{C_{\text {chanel }}}=\frac{p_{\mathrm{H}_{2}}^{C_{\text {in }}}+p_{\mathrm{H}_{2}}^{C_{\text {out }}}}{2}
$$

where $p_{\mathrm{H}_{2}}^{C_{\text {chanel }}}$ is the pressure of hydrogen of the air supply channel; $p_{\mathrm{H}_{2}}^{C_{\text {in }}}$ is the inlet pressure of hydrogen of the air supply channel; $p_{\mathrm{H}_{2}}^{C_{\text {out }}}$ is the outlet pressure of hydrogen of the air supply channel.

The pressure of oxygen based on Faraday Law is described as [25],

$$
p_{\mathrm{O}_{2}}^{C_{\text {channel }}}=\frac{p_{\mathrm{O}_{2}}^{C_{\text {in }}}+p_{\mathrm{O}_{2}}^{C_{\text {out }}}}{2}
$$

where $p_{\mathrm{O}_{2}}^{C_{\text {chanel }}}$ is the channel oxygen pressure; $p_{\mathrm{O}_{2}}^{C_{\text {in }}}$ is the channel inlet oxygen pressure; $p_{\mathrm{O}_{2}}^{C_{\text {out }}}$ is the channel outlet oxygen pressure.

The steam pressure based on Faraday Law is described as [25],

$$
p_{\mathrm{H}_{2} \mathrm{O}}^{C_{\text {camel }}}=\frac{p_{\mathrm{H}_{2} \mathrm{O}}^{C_{\text {in }}}+p_{\mathrm{H}_{2} \mathrm{O}}^{C_{\text {out }}}}{2}
$$

where $p_{\mathrm{H}_{2} \mathrm{O}}^{C_{\text {chanel }}}$ is the pressure of steam of the channel; $p_{\mathrm{H}_{2} \mathrm{O}}^{C_{\text {in }}}$ is the inlet pressure of steam of the channel; $p_{\mathrm{H}_{2} \mathrm{O}}^{C_{\text {out }}}$ is the outlet pressure of steam of the channel.

The hydrogen conservation based on Faraday Law is described as [26],

$$
M_{\mathrm{H}_{2}}^{C_{\text {in }}}-M_{\mathrm{H}_{2}}^{C_{\text {out }}}=\frac{I}{2 F}
$$

where $M_{\mathrm{H}_{2}}^{C_{\text {in }}}$ is the mass of hydrogen in the channel inlet; $M_{\mathrm{H}_{2}}^{C_{\text {out }}}$ is the mass of hydrogen in the channel outlet; $I$ is the current generated by the TGSOFC; $F$ is the Faraday constant.

The mass conservation of oxygen based on Faraday Law is described as [26],

$$
M_{\mathrm{O}_{2}}^{C_{\text {in }}}-M_{\mathrm{O}_{2}}^{C_{\text {out }}}=\frac{I}{4 F}
$$

where $M_{\mathrm{O}_{2}}^{C_{\text {in }}}$ is the mass of oxygen in the channel inlet; $M_{\mathrm{O}_{2}}^{C_{\text {out }}}$ is the mass of oxygen in the channel outlet.

The mass conservation of steam based on Faraday Law is described as [26],

$$
M_{\mathrm{H}_{2} \mathrm{O}}^{C_{\text {in }}}-M_{\mathrm{H}_{2} \mathrm{O}}^{C_{\text {out }}}=-\frac{I}{2 F}
$$

where $M_{\mathrm{H}_{2} \mathrm{O}}^{C_{\text {in }}}$ is the mass of steam in the channel inlet; $M_{\mathrm{H}_{2} \mathrm{O}}^{C_{\text {out }}}$ is the mass of steam in the channel outlet.

The conservation of gas mass inside of the air supply channels is described as [27]:

$$
M_{\text {anode }}^{C_{\text {out }}}=M_{\text {anode }}^{C_{\text {in }}}=M_{\mathrm{H}_{2}}^{C_{\text {in }}}+M_{\mathrm{H}_{2} \mathrm{O}}^{C_{\text {in }}}
$$

where $M_{\text {anode }}^{C_{\text {in }}}$ is the total mass of gas entering anode; $M_{\text {anode }}^{C_{\text {out }}}$ is the total mass of gas leaving anode, which can be represented as [27],

$$
M_{\text {cathode }}^{C_{\text {out }}}=M_{\text {cathode }}^{C_{\text {in }}}
$$

The conservation of gas mass at the air supply channels inlet and outlet are displayed as [27], 


$$
\left\{\begin{array}{l}
M_{\mathrm{H}_{2}}^{C_{\text {in }}}=M_{\text {anode }} \frac{p_{\mathrm{H}_{2}}^{C_{\text {in }}}}{p_{\text {anode }}^{C_{\text {in }}}} \\
M_{\mathrm{H}_{2}}^{C_{\text {out }}}=M_{\text {anode }} \frac{p_{\mathrm{H}_{2}}^{C_{\text {out }}}}{p_{\text {anode }}^{C_{\text {out }}}}
\end{array}\right.
$$

where $M_{\text {anode }}$ means the mass of anode; $p_{\text {anode }}^{C_{\text {in }}}$ and $p_{\text {anode }}^{C_{\text {out }}}$ mean the total pressure of gas living and entering anodes, respectively.

The steam mass of air supply channels inlet and the steam mass of air supply channels outlet are displayed as [27],

$$
\left\{\begin{array}{l}
M_{\mathrm{H}_{2} \mathrm{O}}^{C_{\text {in }}}=M_{\text {anode }} \frac{p_{\mathrm{H}_{2} \mathrm{O}}^{C_{\text {in }}}}{p_{\text {anode }}^{C_{\text {in }}}} \\
M_{\mathrm{H}_{2} \mathrm{O}}^{C_{\text {out }}}=M_{\text {anode }} \frac{p_{\mathrm{H}_{2} \mathrm{O}}^{C_{\text {out }}}}{p_{\text {anode }}^{C_{\text {out }}}}
\end{array}\right.
$$

The mass of oxygen at the inlet of air supply channels; and the mass of oxygen of air supply channels outlet are displayed as [27],

$$
\left\{\begin{array}{l}
M_{\mathrm{O}_{2}}^{C_{\text {in }}}=M_{\text {anode }} \frac{p_{\mathrm{O}_{2}}^{C_{\text {in }}}}{p_{\text {cathode }}^{C_{\text {can }}}} \\
M_{\mathrm{O}_{2}}^{C_{\text {out }}}=M_{\text {anode }} \frac{p_{\mathrm{O}_{2}}^{C_{\text {out }}}}{p_{\text {cathode }}^{C_{\text {cat }}}}
\end{array}\right.
$$

where $p_{\text {cathode }}^{C_{\text {in }}}$ is the total pressure of gas entering anode; $p_{\text {cathode }}^{C_{\text {out }}}$ is the total pressure of gas living anode.

The fuel efficiency of a TGSOFC is defined as [13]:

$$
\eta=\frac{I}{2 F} / M_{\mathrm{H}_{2}}^{C_{\text {in }}}
$$

where $\eta$ is the fuel efficiency of the TGSOFC.

\subsection{Thermal equilibrium of tubular grid-connected solid oxide fuel cells}

The electrochemical reaction of TGSOFCs, which occurs in the layer of the electrode-electrolyte, can generate heat. The electric energy generated by the electrochemical reaction is transferred to the systemic power load. The generated heat of TGSOFCs is dissipated between the electrodes and the electrolyte. In the air supply channel inlet of TGSOFCs, a cooling device is installed into the layer between electrodes and electrolyte to cool the fuel and air flows. Simultaneously, a small part of the generated heat by TGSOFCs diverts to the air supply channel by thermal transmission. The internal cross-section and the thermal transmission process of the chemical reaction of the TGSOFC are shown in Fig. 3.

The air temperature of the air supply tube of TGSOFCs is equal to the average of the air temperature at the channel inlet and the annulus air temperature of the air supply tube, as [28]:

$$
T_{\text {air,air supply tube }}=\frac{T_{\text {air, } \mathrm{C}_{\text {in }}}+T_{\text {air,air supply tube,annulus }}}{2}
$$


where $T_{\text {air,air supply tube }}$ is the channel air temperature of TGSOFC; $T_{\mathrm{air}, \mathrm{C}_{\mathrm{in}}}$ is the air temperature of the channel inlet of TGSOFC; $T_{\text {air,air supply tube,annulus }}$ is the air temperature at the annulus of the air supply tube of TGSOFC.

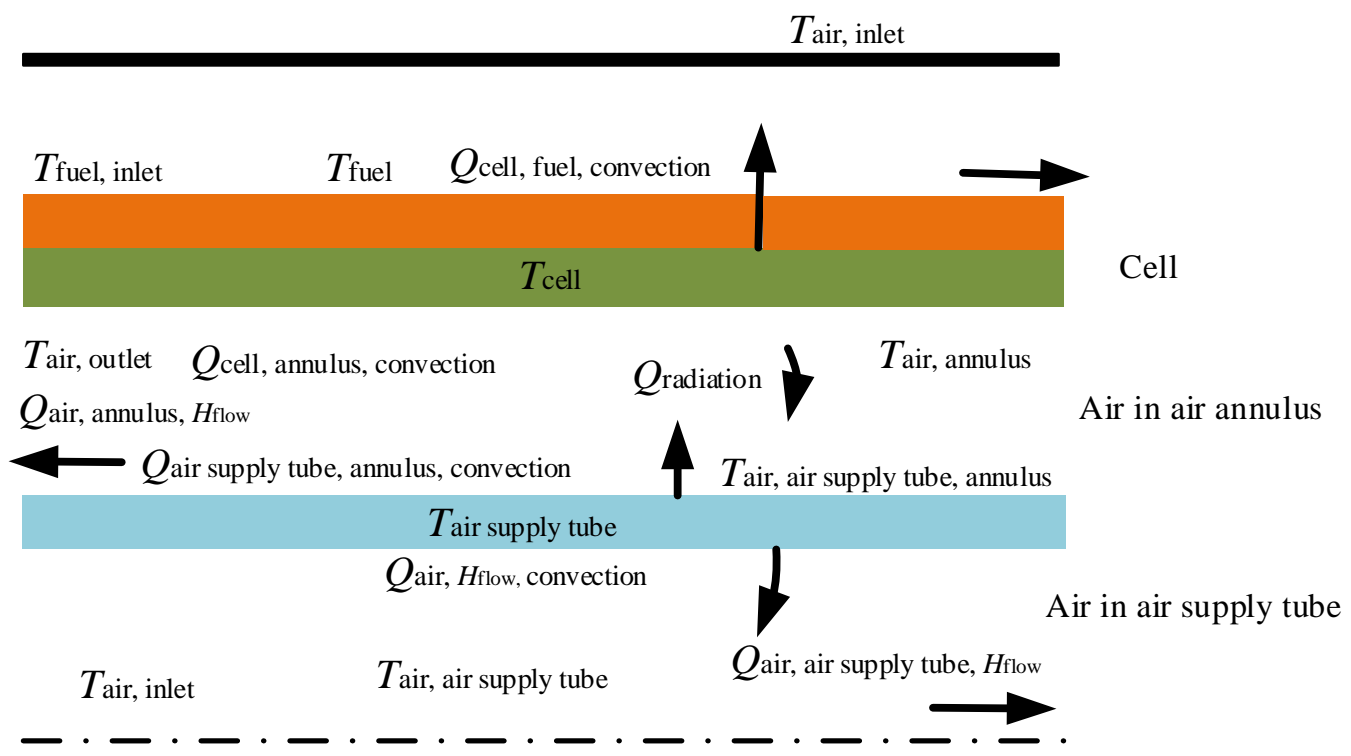

Fig. 3. Thermal transmission process of tubular grid-connected solid oxide fuel cell

The annulus air temperature of TGSOFC is equal to the average air temperature of the channel outlet and the annulus of the air supply tube of TGSOFC, as [28]:

$$
T_{\text {air,annulus }}=\frac{T_{\text {air, } \mathrm{C}_{\text {out }}}+T_{\text {air,air supply tube,annulus }}}{2}
$$

where $T_{\text {air,annulus }}$ is the air temperature of the annulus of the TGSOFC; $T_{\text {air, } C_{\text {out }}}$ is the air temperature of the channel outlet of the TGSOFC.

The fuel temperature of TGSOFC is equal to the average fuel temperature of the channel inlet and outlet of TGSOFC, as [28]:

$$
T_{\text {fuel }}=\frac{T_{\text {fuel, } \mathrm{C}_{\text {in }}}+T_{\text {fuel, }, \mathrm{C}_{\text {out }}}}{2}
$$

where $T_{\text {fuel }}$ is the fuel temperature of the TGSOFC; $T_{\text {fuel, } C_{\text {in }}}$ and $T_{\text {fuel, } \mathrm{C}_{\text {out }}}$ are the channel inlet and outlet temperatures of the TGSOFC, respectively.

In the electrode-electrolyte layer of the TGSOFC, the heat generated by the electrochemical reaction of the TGSOFC is transferred by three parts, i.e., the radiation consumed of the TGSOFC, the heat loss caused by the conversion between air supply tube and annulus of the TGSOFC, and the heat loss caused by fuel transfer between the annulus and the supply tube of the TGSOFC [28]:

$$
Q_{\text {chemical }}-V_{C_{\text {out }}} \cdot I=Q_{\text {radiation }}+Q_{\text {cell,annulus,convection }}+Q_{\text {cell,fuel,convection }}
$$

where $Q_{\text {chemical }}$ is the heat generated by the chemical reactions of TGSOFC; $V_{C_{\text {out }}}$ is the output voltage of TGSOFC; $Q_{\text {radiation }}$ is the radiation consumed of TGSOFC; $Q_{\text {cell,annulus,convection }}$ is the heat loss caused by the conversion between the air supply tube and the annulus of TGSOFC; $Q_{\text {cell,fuel,convection }}$ is the heat loss caused by fuel transfer between the annulus and the supply tube of TGSOFC. 
Eq. (16) includes the heat consumed by the internal resistance of the TGSOFC and the thermal transmission ways of the TGSOFC.

The heat generated by the fuel combustion of the TGSOFC can be described as [29]:

$$
Q_{\text {fuel, } H_{\text {flow }}}=Q_{\text {cell,fuel,convection }}
$$

where $Q_{\text {fuel, } H_{\text {flow }}}$ is the heat transmission of fuel combustion of TGSOFC.

The heat of air between the cell and the air supply tube of the TGSOFC can be presented as [29]:

$$
Q_{\text {air,annulus, } H_{\text {flow }}}=Q_{\text {air supply tube,annulus,convection }}+Q_{C_{\text {cell }} \text {,annulus,convection }}
$$

where $Q_{\text {air,annulus, } H_{\text {flow }}}$ is the heat carried by air at the annulus of TGSOFC; $Q_{\text {air supply tube,annulus,convection }}$ is the heat transfer between the annulus and the air supply tube of TGSOFC.

The heat of the air supply tube of the TGSOFC can be calculated as [29]:

$$
Q_{\text {radiation }}=Q_{\text {air supply tube, } H_{\text {iner }} \text {, convection }}+Q_{\text {air supply tube,annulus, convection }}
$$

where $Q_{\text {air supply tube, } H_{\text {iner }} \text {, convection }}$ is the heat convection at the inner of the air supply tube of TGSOFC; $Q_{\text {air supply tube,annulus,convection }}$ is the heat convection at the annulus of the air supply tube of TGSOFC.

The heat of the air of air supply tube of TGSOFC can be displayed [29]:

$$
Q_{\text {air,air supply tube, } H_{\text {flow }}}=Q_{\text {air supply tube,inside,convection }}
$$

where $Q_{\text {air,air supply tube, } H_{\text {flow }}}$ is the heat of air flowing at the air supply tube of the TGSOFC; $Q_{\text {air supply tube,inside,convection }}$ is the heat convection of the air supply tube of the TGSOFC.

The heat generated by the chemical reactions of the TGSOFC $Q_{\text {chemical }}$ can be calculated as [29]:

$$
Q_{\text {chemical }}=n_{H_{2}, \text { consumed }} \cdot \Delta \mathrm{H}=\frac{I}{2 F} \cdot \Delta \mathrm{H}
$$

where $n_{H_{2} \text {,consumed }}$ is the moles of hydrogen consumed by the chemical reactions of the TGSOFC; $\Delta \mathrm{H}$ is the entropy of hydrogen in the chemical reactions of the TGSOFC.

The radiation consumed of the TGSOFC $Q_{\text {radiation }}$ can be calculated as [29]:

$$
Q_{\text {radiation }}=\varepsilon_{\text {air supply tube }}^{*} \sigma A_{\text {air supply tube, } H_{\text {outer }}}\left(T_{C_{\text {cell }}^{4}}^{4}-T_{C_{\text {air supply tube }}^{4}}^{4}\right)
$$

where $\varepsilon_{\text {air supply tube }}^{*}$ is the emissivity constant of a chemical reaction of the TGSOFC; $\sigma$ is the Stefan-Boltzmann constant; $A_{\text {air supply tube, } H_{\text {outer }}}$ is the reaction area of air supply tube of the TGSOFC; $T_{C_{\text {cell }}}^{4}$ is the fourth power of temperature in reaction cell of the TGSOFC; $T_{C_{\text {air supply ybe }}^{4}}$ is the fourth power of temperature in air supply tube of the TGSOFC.

The heat loss caused by the conversion between the air supply tube and the annulus of the TGSOFC can be calculated as [29]:

$$
Q_{C_{\text {cell }, \text { annulus,convection }}}=h_{C_{\text {cell }}} A_{C_{\text {cell }}, H_{\text {iner }}}\left(T_{C_{\text {cell }}}-T_{\text {air,annulus }}\right)
$$


where $h_{C_{\text {cell }}}$ is the convective heat-transfer constant of the chemical reaction of the TGSOFC; $A_{C_{\text {cell }}, H_{\text {iner }}}$ is the inner reaction area of the TGSOFC; $T_{C_{\text {cell }}}$ is the temperature of the TGSOFC.

The heat loss caused by fuel transfer between the annulus and the supply tube of the TGSOFC can be calculated as [29]:

$$
Q_{C_{\text {cell }}, \text { fuel, convection }}=h_{C_{\text {cell }}} A_{C_{\text {cell }}, H_{\text {outer }}}\left(T_{C_{\text {cell }}}-T_{\text {fuel }}\right)
$$

The heat transfer between the annulus and the air supply tube of the TGSOFC can be calculated as [30]:

$$
Q_{\text {air supply tube,annulus,convection }}=h_{\text {air supply tube, } H_{\text {outer }}} A_{\text {air supply tube, } H_{\text {outer }}}\left(T_{\text {air }, C_{\text {cell }}}-T_{\text {air supply tube }}\right)
$$

where $h_{\text {air supply tube, } H_{\text {outer }}}$ is the convective heat-transfer constant of the channel outlet of the TGSOFC; $A_{\text {air supply tube }, H_{\text {outer }}}$ is the reaction area of the outlet of the TGSOFC; $T_{\text {air }, C_{\text {cell }}}$ is the air temperature of the TGSOFC; $T_{\text {air supply tube }}$ is the air supply tube temperature during the chemical reaction process of the TGSOFC.

The heat of convection of the air supply tube of the TGSOFC can be presented as [29]:

$$
Q_{\text {air supply tube, } H_{\text {iner }}, \text { convection }}=h_{\text {air supply tube, } H_{\text {inner }}} A_{\text {air supply tube, } H_{\text {iner }}}\left(T_{\text {air supply tube }}-T_{\text {air,air supply tube }}\right)
$$

The heat of the air in the annulus of the TGSOFC can be presented as [29]:

$$
Q_{\text {air,annulus, } H_{\text {flow }}}=M_{\text {cathode }} M_{\text {Molar mass,air }} C_{\text {air }}\left(T_{\text {air }, C_{\text {out }}}-T_{\text {air,air supply tube,annulus }}\right)
$$

where $M_{\text {Molar mass,air }}$ is the Molar mass of air during the chemical reaction process of the TGSOFC; $C_{\text {air }}$ means the air heat capacity of the TGSOFC.

$$
\begin{gathered}
Q_{\text {air,air supply tube, } H_{\text {flow }}}=M_{\text {cathode }} M_{\text {Molar mass,air }} C_{\text {air }}\left(T_{\text {air,air supply tube,annulus }}-T_{\text {air, }, \mathrm{C}_{\text {in }}}\right) \\
\left\{\begin{array}{l}
Q_{\text {fuel }, H_{\text {flow }}}=Q_{\mathrm{H}_{2}, H_{\text {flow }}}+Q_{\mathrm{H}_{2} \mathrm{O}, H_{\text {flow }}} \\
Q_{\mathrm{H}_{2}, H_{\text {flow }}}=\left(M_{\mathrm{H}_{2}}^{C_{\text {in }}}+M_{\mathrm{H}_{2}}^{C_{\text {out }}}\right)\left(T_{\text {fuel }}^{C_{\text {out }}}-T_{\text {fuel }}^{C_{\text {in }}}\right) C_{\mathrm{H}_{2}} M_{\text {Molar mass, } \mathrm{H}_{2}} \\
Q_{\mathrm{H}_{2} \mathrm{O}, \mathrm{H}_{\text {flow }}}=\left(M_{\mathrm{H}_{2} \mathrm{O}}^{C_{\text {in }}}+M_{\mathrm{H}_{2} \mathrm{O}}^{C_{\text {out }}}\right)\left(T_{\text {fuel }}^{C_{\text {out }}}-T_{\text {fuel }}^{C_{\text {in }}}\right) C_{\mathrm{H}_{2} \mathrm{O}} M_{\text {Molar mass }, \mathrm{H}_{2} \mathrm{O}}
\end{array}\right.
\end{gathered}
$$

where $M_{\text {Molar mass, } \mathrm{H}_{2}}$ is the hydrogen Molar mass of the TGSOFC; $C_{\mathrm{H}_{2}}$ means the hydrogen heat capacity of the TGSOFC; $M_{\text {Molar mass }, \mathrm{H}_{2} \mathrm{O}}$ is the steam Molar mass of the TGSOFC; $C_{\mathrm{H}_{2} \mathrm{O}}$ is the steam heat capacity of of the TGSOFC.

\subsection{Electric energy transfer in the chemical reaction}

The open-circuit potential of TGSOFC obeys Nernst Equation, as [28]:

$$
E_{C_{\text {cell }}}=E_{C_{\text {cell }}, 0}-k_{E}\left(T_{C_{\text {cell }}}-273\right)+\frac{R T_{C_{\text {cell }}}}{4 F} \ln \left[\frac{\left(p_{\mathrm{H}_{2}}^{*}\right)^{2} p_{\mathrm{O}_{2}}^{*}}{\left(p_{\mathrm{H}_{2} \mathrm{O}}^{*}\right)^{2}}\right]
$$

where $E_{C_{\text {cell }}, 0}$ is the electric reference potential of TGSOFC; $R$ is the resistance of the systemic load; $p_{\mathrm{H}_{2}}^{*}$ is the effective hydrogen pressure of the chemical reaction process of the TGSOFC; $p_{\mathrm{O}_{2}}^{*}$ is the effective oxygen pressure of the chemical reaction process of the TGSOFC; $p_{\mathrm{H}_{2} \mathrm{O}}^{*}$ is the effective steam pressure of the chemical reaction process of the TGSOFC. 
For the electrochemical reaction of a TGSOFC, the reference open-loop electrode potential is $1.229 \mathrm{~V}$ [31]. The multifarious voltage drop is presented as $E_{C_{\text {cell }}}$. The voltage drop caused by activation reactant, the voltage drop of ohmic resistance consumed by circuit load, and the voltage drop caused by concentration decreasing after the chemical reaction of the TGSOFC lead to the inner voltage drop of the TGSOFC. Thus, the calculation Eq. (30) of the output voltage of the TGSOFC can be rewritten as [28]:

$$
V_{C_{\text {cell }}}=E_{C_{\text {cell }}}-V_{\text {activation, } C_{\text {cell }}}-V_{\text {ohmic, } C_{\text {cell }}}-V_{\text {concentration, } C_{\text {cell }}}
$$

where $V_{\text {activation, } C_{\text {cell }}}$ is the voltage drop with the activation reactant of TGSOFC; $V_{\text {ohmic, } C_{\text {cell }}}$ is the voltage drop of ohmic resistance of TGSOFC; $V_{\text {concentration, } C_{\text {cell }}}$ is the concentration voltage drop after the chemical reaction of TGSOFC.

The concentration voltage drop after the chemical reaction of the TGSOFC can be calculated as [28]:

$$
V_{\text {concentration, } C_{\text {cell }}}=\frac{R T_{C_{\text {cell }}}}{4 F}\left\{\ln \left[\frac{\left(p_{\mathrm{H}_{2}}^{C_{\text {chamel }}}\right)^{2} p_{\mathrm{O}_{2}}^{*}}{\left(p_{\mathrm{H}_{2} \mathrm{O}}^{\mathrm{C}_{\text {chanel }}}\right)^{2}}\right]-\ln \frac{\left(p_{\mathrm{H}_{2}}^{*}\right)^{2} p_{\mathrm{O}_{2}}^{*}}{\left(p_{\mathrm{H}_{2} \mathrm{O}}^{*}\right)^{2}}\right\}
$$

where $p_{\mathrm{H}_{2}}^{C_{\text {chanel }}}$ is the channel hydrogen pressure of TGSOFC; $p_{\mathrm{H}_{2} \mathrm{O}}^{\mathrm{C}_{\text {chanel }}}$ is the channel steam pressure of TGSOFC.

The voltage drop caused by the activation decreasing after the chemical reaction of the TGSOFC can be calculated as [28]:

$$
V_{\text {activation, } C_{\text {cell }}}=\zeta_{0}+\zeta_{1} T_{C_{\text {cell }}}+\frac{2 R T_{C_{\text {cell }}}}{z F} \sinh ^{-1}\left(\frac{I}{2 I_{0}}\right)
$$

where $z$ the number of participating electrons of TGSOFC; both $\zeta_{0}$ and $\zeta_{1}$ are the voltage drop coefficients caused by the activation decreasing after the chemical reaction of TGSOFC.

The activation resistance of TGSOFC can be presented as [28]:

$$
R_{\text {activation, } C_{\text {cell }}}=\frac{2 R T_{C_{\text {cell }}}}{z F I} \sinh ^{-1}\left(\frac{I}{2 I_{0}}\right)
$$

The inner voltage drop of the TGSOFC can be described as [28]:

$$
V_{\text {ohmic }, C_{\text {cell }}}=\frac{a_{\text {electrolyte }} \exp \left(b_{\text {electrolyte }} / T_{C_{\text {cell }}}\right)}{A_{C_{\text {cell }}}} \delta_{\text {electrolyte }}+\frac{a_{C_{\text {interconnection }}} \exp \left(b_{C_{\text {intercomection }}} / T_{C_{\text {cell }}}\right)}{A_{C_{\text {cell }}}} \delta_{C_{\text {interconnection }}}
$$

where both $a_{\text {electrolyte }}$ and $b_{\text {electrolyte }}$ are the electrolyte resistance constants of TGSOFC; $\delta_{\text {electrolyte }}$ is the thickness of the electrolyte of the TGSOFC; both $a_{C_{\text {intercomection }}}$ and $b_{C_{\text {interesonection }}}$ are the material resistances of interconnection between multiple TGSOFCs; $\delta_{C_{\text {intercomection }}}$ is the thickness of interconnection between multiple TGSOFCs.

\section{Adaptive multistep model predictive control}

Adaptive control and multiple MPCs stack the proposed AMMPC.

\subsection{Model predictive control}

The MPC structure includes a model, a predictor, and a controller (Fig. 4). 


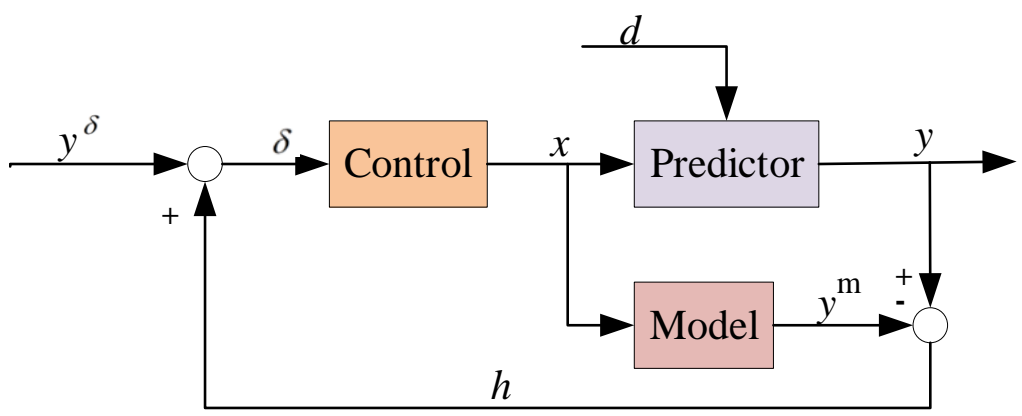

Fig. 4. Structure chart of model predictive control

With systemic disturbance, the objective function of the MPC can be designed as follows [32]:

$$
J=\sum_{\psi=1}^{M} \sum_{\theta=1}^{P}\left[y_{\psi, t+\theta}^{s}-\left(y_{\psi, t+\theta}^{m}+h_{\psi, t}\right)\right]^{2}+\sum_{\phi=1}^{N} \sum_{\lambda=1}^{C} w_{\phi, \lambda} \Delta x_{\phi, t+\lambda}^{2}
$$

Where $x$ and $y$ are manipulated and output variables, respectively; $M$ and $N$ are the controlled and manipulated variables of MPC, respectively; $P$ and $C$ are the prediction and control horizons of MPC, respectively; $y_{\psi, t+\theta}^{s}$ and $y_{\psi, t+\theta}^{m}$ are the setpoint and predicted values of the controlled variable $\psi$, respectively; $t$ is the step number of current time; $w_{\phi, \lambda}$ is the weight of variable $\phi$ of the $\lambda$ iteration in the control horizon; $\Delta x_{\phi, t+\lambda}$ is the increment of the variable $\phi$ of the $\lambda$ iteration in the control horizon.

The following constraints should be satisfied for the manipulated variables to obtain the increments [33].

$$
\left\{\begin{array}{l}
P \geq C \\
x_{\phi, t+\lambda}=x_{\phi, t+C}(\lambda>C, \phi=1,2, \ldots, N) \\
\left|\Delta x_{\phi, t+\lambda}\right| \leq \Delta x_{\phi, \text { max }}(\phi=1,2, \ldots, N ; \lambda=1,2, \ldots, C) \\
x_{\phi, \text { min }} \leq x_{\phi, t+\lambda} \leq x_{\phi, \text { max }}(\phi=1,2, \ldots, N) \\
y_{\psi, \text { min }} \leq y_{\psi, t+\theta}^{m} \leq y_{\psi, \text { max }}(\psi=1,2, \ldots, M ; \theta=1,2, \ldots, P)
\end{array}\right.
$$

where $x_{\phi, \min }$ and $x_{\phi, \max }$ are the lower and upper bounds of the variable $\phi$, respectively; $x_{\phi}$ is the manipulated variable of the $\phi ; \Delta x_{\phi}$ is the increment of the manipulated variable $\phi[33]$ :

$$
\Delta x_{\phi, t+\lambda}=x_{\phi, t+\lambda}-x_{\phi, t+\lambda-1}(\phi=1,2, \ldots, N ; \lambda=1,2, \ldots, C)
$$

where $y_{\psi, \min }$ and $y_{\psi, \max }$ are the low and upper bounds of the variable $\psi$, respectively; the difference between mensuration and prediction is calculated as [33]:

$$
h_{\psi, t}=y_{\psi, t}-y_{\psi, t}^{m}
$$

where $h_{\psi, t}$ is the difference between measured values and predicted values; $y_{\psi, t}$ and $y_{\psi, t}^{m}$ mean the measured and feedforward functions in the $\psi$ th iteration, respectively.

Multiple outputs controller with two outputs can be presented as $y=\left[y_{1}, y_{2}\right]^{\mathrm{T}}$. Multiple inputs controller with two inputs is expressed as $u=\left[u_{1}, u_{2}\right]^{\mathrm{T}}$. The output function of the MPC is $Y(s) ; G(s)$ is the transfer function of the MPC; $U(s)$ is the input function of the AMMPC; $\delta(s)$ is the disturbance function. The transfer function of the controlled systems is described as follows: 


$$
Y(s)=G(s) \cdot U(s)+\delta(s)
$$

The output predicted by the MPC is constructed as:

$$
\hat{y_{i}}(s)=G_{i j}(s)\left(u_{i j}(s)+\hat{\sigma}_{i j}(s)\right)
$$

where $G_{i j}(s)$ is the positive element of $G(s)$ when the $i=j ; \hat{\sigma}_{i j}(s)$ is the predicted estimate function by MPC.

\subsection{Adaptive multistep model predictive control}

The AMMPC is inspired by the MPC. The control performance of an MPC depends on the prediction steps and the final outputs of the MPC. The AMMPC contains adaptive control and multistep MPC. The adaptive control of the AMMPC aims to reduce the negative effect of the outside disturbance fluctuation. The multistep MPC of AMMPC aims to predict the next systemic outputs. The prediction accuracy of the next systemic outputs relies on the multistep MPC of the AMMPC. While multiple weighted predictions decide the prediction accuracy of the multistep MPC of the AMMPC. Consequently, the systemic stability can be increased by multistep MPC rather than single-step MPC.

The adaptive control law is applied to update the estimation $\hat{\sigma}_{i j}(s)$, which is presented as [34]:

$$
\left\{\begin{array}{l}
\hat{\sigma}_{i}(s)=\rho q_{\text {Projection }}\left(\hat{\sigma}_{i}-\left(y_{i}-y_{i}\right)\right) \\
\sigma(0)=0
\end{array}\right.
$$

where $\rho$ is the adaptation rate of the controlled objective; $q_{\text {Projection }}$ expresses the projection operator of controlled systems, which guarantees the estimation value is bounded [35].

The predicted outputs of the AMMPC are described as,

$$
Y\left(k T_{\mathrm{AMMPC}}\right)=\sum_{i=1}^{N_{\text {step }}} \varepsilon_{i} Y\left(k T_{\mathrm{MPC}}\right)
$$

where $Y\left(k T_{\mathrm{AMMPC}}\right)$ is the predicted output of the AMMPC; $Y\left(k T_{\mathrm{MPC}}\right)$ is the output predicted by the MPC; $N_{\text {step }}$ is the number of steps of the AMMPC; $\varepsilon_{i}$ is the weighted coefficient of each AMMPC, which should satisfy the following condition.

$$
\sum_{i=1}^{N_{\text {step }}} \varepsilon_{i}=1
$$

If $N_{\text {step }}$ is set to be two, the AMMPC with two steps is named AMMPC-II; if $N_{\text {step }}$ is set to be three, the AMMPC with three steps is named AMMPC-III. Each weighted coefficient of AMMPC should be configured for real-life projects.

\subsection{Flow chart of adaptive multistep model predictive control for tubular grid-connected solid oxide}

\section{fuel cells}

A multiple-output controller with two outputs can be presented as

$$
y=\left[y_{1}, y_{2}\right]^{\mathrm{T}}=\left[V_{C_{\text {out }}}, \eta\right]^{\mathrm{T}} .
$$

Then, the input hydrogen and oxygen are expressed as 


$$
u=\left[u_{1}, u_{2}\right]^{\mathrm{T}}=\left[M_{\mathrm{H}_{2}}, M_{\mathrm{Air}}\right]^{\mathrm{T}} .
$$

To avoid fuel efficiency exceeds the upper bound (90\%) [13], $\eta_{\text {upper }}$ is the upper bound of the fuel efficiency $\eta$. The lower bound of hydrogen flow should be updated with the reference current at each iteration, as:

$$
\eta_{1, \text { min }}=\frac{I_{\text {ref }}}{2 F \cdot \eta_{\text {upper }}}
$$

After the setpoints scheduler of the TGSOFC provides the voltage value for the AMMPC, the AMMPC provides the hydrogen for the TGSOFC. Meanwhile, to satisfy the operation safety of TGSOFC, the fuel efficiency of the TGSOFC system should be maintained between $70 \%$ and $90 \%$ [14]. The AMMPC method is designed to improve fuel efficiency by regulating the fuel flow and airflow of TGSOFC.

Fig. 5 shows the power system with a TGSOFC. In Fig. 5, the input quantities include: (i) the pressures of anode and cathode; (ii) the flow rate of $\mathrm{H}_{2}, \mathrm{H}_{2} \mathrm{O}$, and air; (iii) the initial temperature of the TGSOFC and air. The TGSOFC temperature is calculated with a reference current in real-time. Then, the load current and temperature are fed back to the AMMPC tracking controllers (Fig. 6), which calculate the output voltage and fuel efficiency of the TGSOFC. In Fig. 5, the pressures of $\mathrm{H}_{2}, \mathrm{H}_{2} \mathrm{O}$, and $\mathrm{O}_{2}$ inflow channels are calculated through Eqs. (7)-(11). Then, Eq. (30) is employed to calculate the internal potential of the TGSOFC. Diffusion Eqs. (16)-(29) calculate the concentration loss of TGSOFC. The ohmic voltage drop and activation voltage are calculated by Eq. (35) and Eq. (33), respectively.

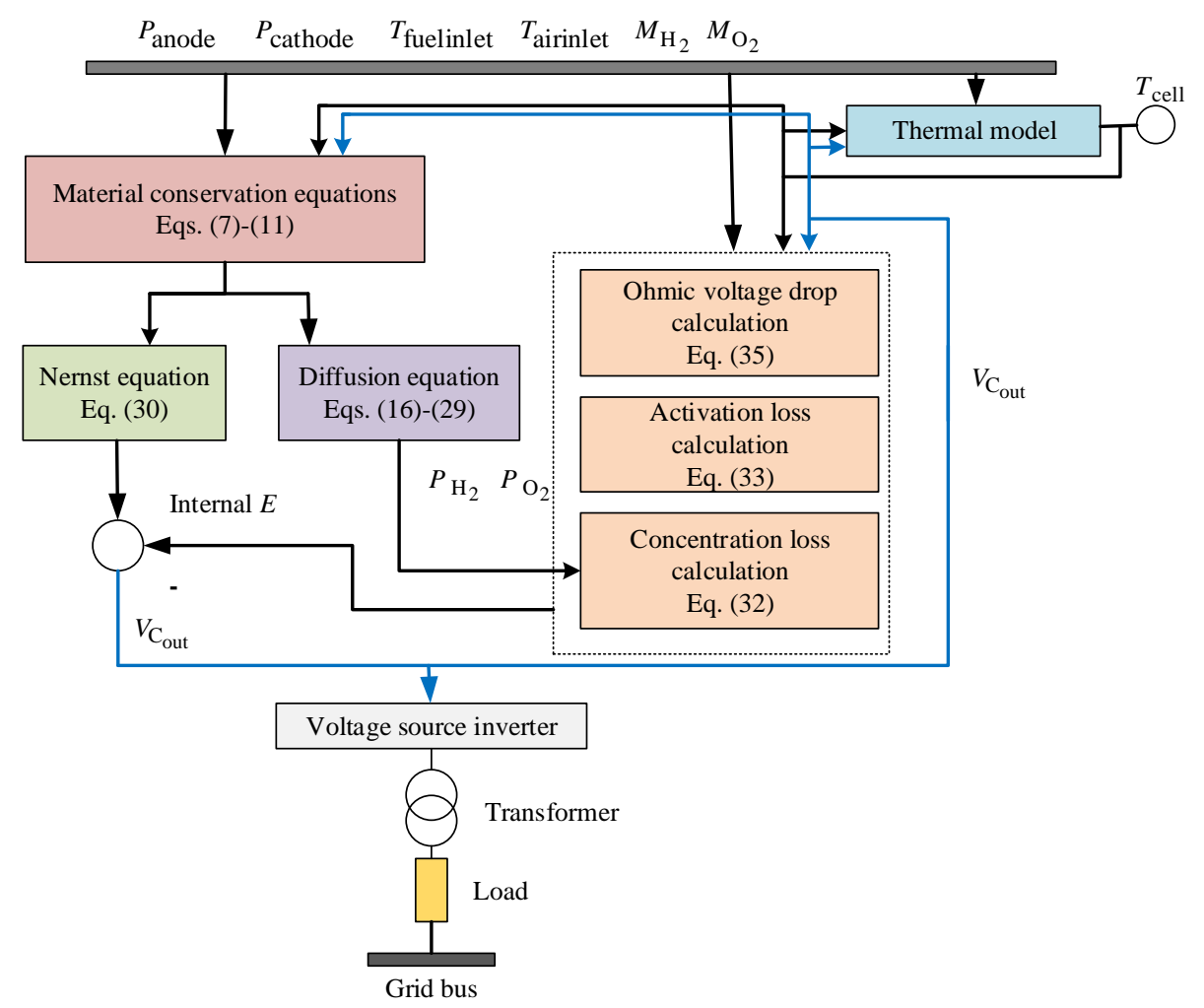

Fig. 5. Power systems based on tubular grid-connected solid oxide fuel cells

In the tracking controller, Fig. 6 shows the AMMPC for a TGSOFC. In Fig. 6, the transfer function of the tracking controller is described as Eqs. (40)-(41); the adaptive value is calculated by Eq. (42); the outputs of 
TGSOFC are calculated by Eq. (36), which satisfies the constraint with Eqs. (37)-(39); the predicted outputs are calculated by Eq. (43), which satisfies the constraint with Eq. (44).

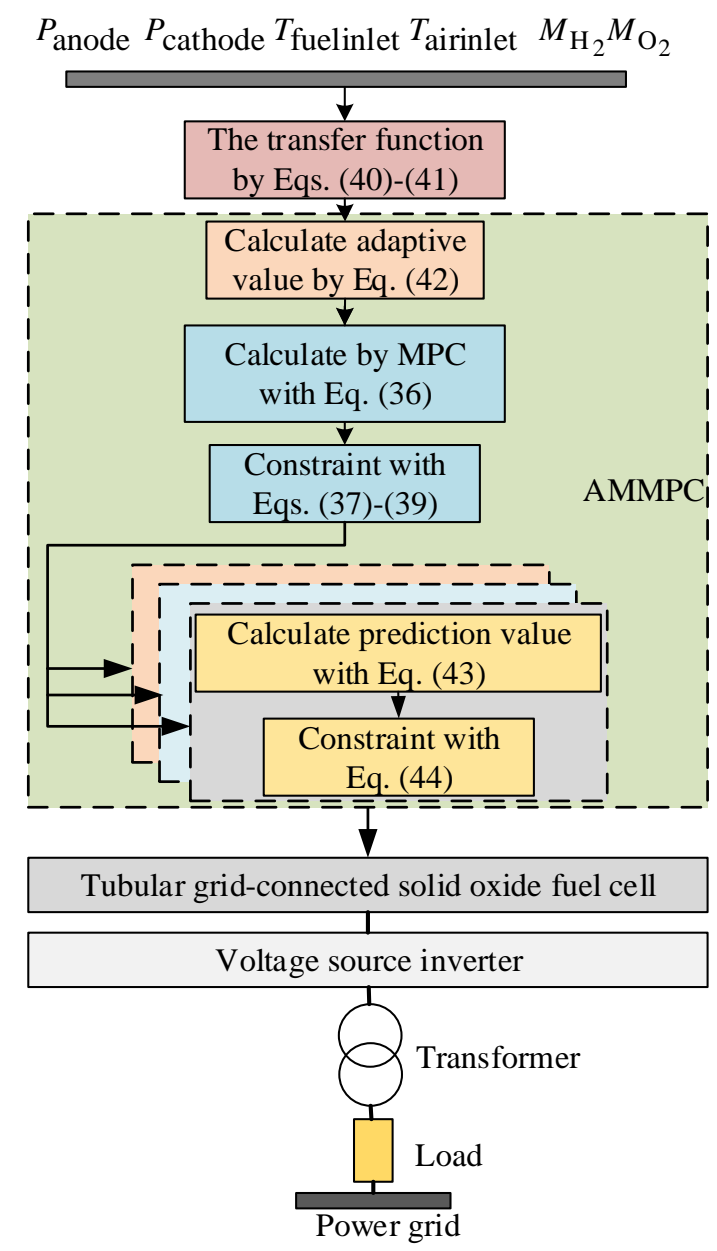

Fig. 6. Calculation steps of adaptive multistep model predictive control for tubular grid-connected solid

\section{Case studies} oxide fuel cells

The control commands of case studies are provided by a personal computer with Intel Core i5-10210U $2.10 \mathrm{GHz}$ and $32 \mathrm{~GB}$ RAM in this paper.

The TGSOFC stack consists of 192 cascaded simple fuel cells. The initial states of the TGSOFC under two cases are configured as follows: output voltage $V_{\mathrm{C}_{\mathrm{out}}}=170.0(\mathrm{~V})$, output current $I=20(\mathrm{~A})$, the active output power is set to $3400 \mathrm{~W}$; the flows of $\mathrm{H}_{2}$ and air are $M_{\mathrm{H}_{2}}=1.5 \times 10^{-5} \mathrm{~mol} / \mathrm{s}$ and $M_{\text {air }}=5 \times 10^{-5} \mathrm{~mol} / \mathrm{s}$, respectively. More parameters of the TGSOFC are given in Appendix 1.

Two cases (i.e., simple and complex power demand cases) are studied to verify the feasibility and effectiveness of the AMMPC. In this paper, four control algorithms are compared under power systems with a TGSOFC. The compared control algorithms include the PID, the adaptive MPC, the AMMPC-II, and the AMMPC-III.

The AMMPC-III and AMMPC-II can provide the output voltage and fuel efficiency by manipulating the inlet air and hydrogen flow of the TGSOFC. Since one PID controller only provides one output, two controllers are designed to control the TGSOFC (Fig. 7). One PID controller is utilized to provide the reference current for the VSI by feedback output power. Another PID controller is employed to provide output voltage 
by dominating hydrogen flow and airflow. Then, the fuel efficiency is feedback to the reference fuel efficiency for the next hydrogen flow regulation.

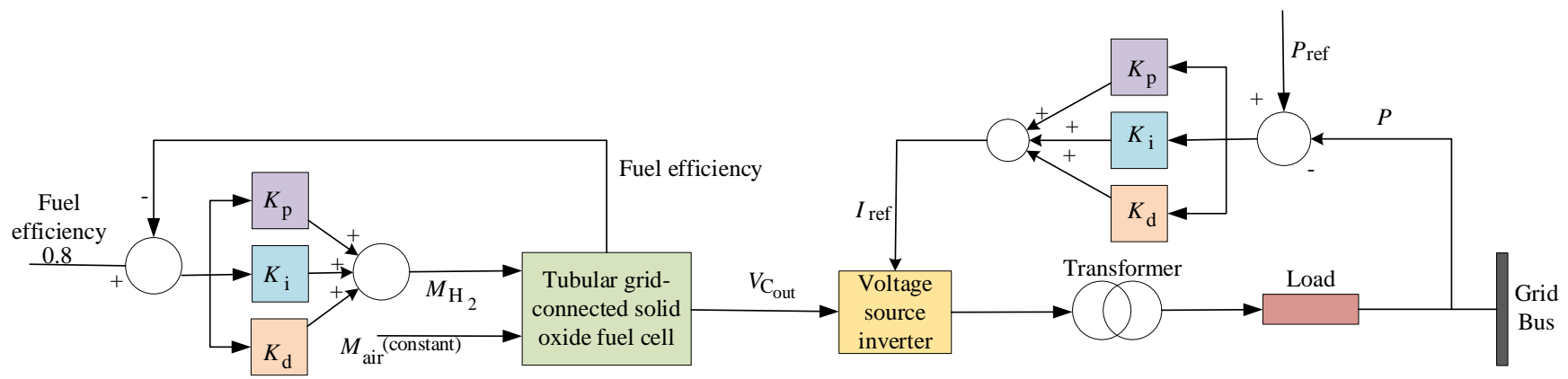

Fig. 7. Proportional-integral-derivative framework of tubular grid-connected solid oxide fuel cells

\subsection{Case of simple power demand (Case I)}

The initial power command of Case I is set to be $P_{\text {ref }}=3500 \mathrm{~W}$. After $100 \mathrm{~s}$, the control system is connected to the TGSOFC system. At time $=300 \mathrm{~s}$, the power demand is set to $P_{\text {ref }}=2750 \mathrm{~W}$; then, the systemic load starts increasing to $P_{\text {ref }}=3500 \mathrm{~W}$ with $5 \mathrm{~W} / \mathrm{s}$ at time $=400 \mathrm{~s}$. $P_{\text {ref }}$ increases to $3650 \mathrm{~W}$ with 1 $\mathrm{W} / \mathrm{s}$ at time $=650 \mathrm{~s}$. $P_{\text {ref }}$ increases to $5000 \mathrm{~W}$ at time $=1000$ s. Finally, the power demand keeps in the 5000 $\mathrm{W}$ to $2000 \mathrm{~s}$. The fuel efficiencies of the TGSOFC obtained by the AMMPC-III with constraint and different weights of three predicted controllers under Case I are shown in Table 1 and Fig. 8.
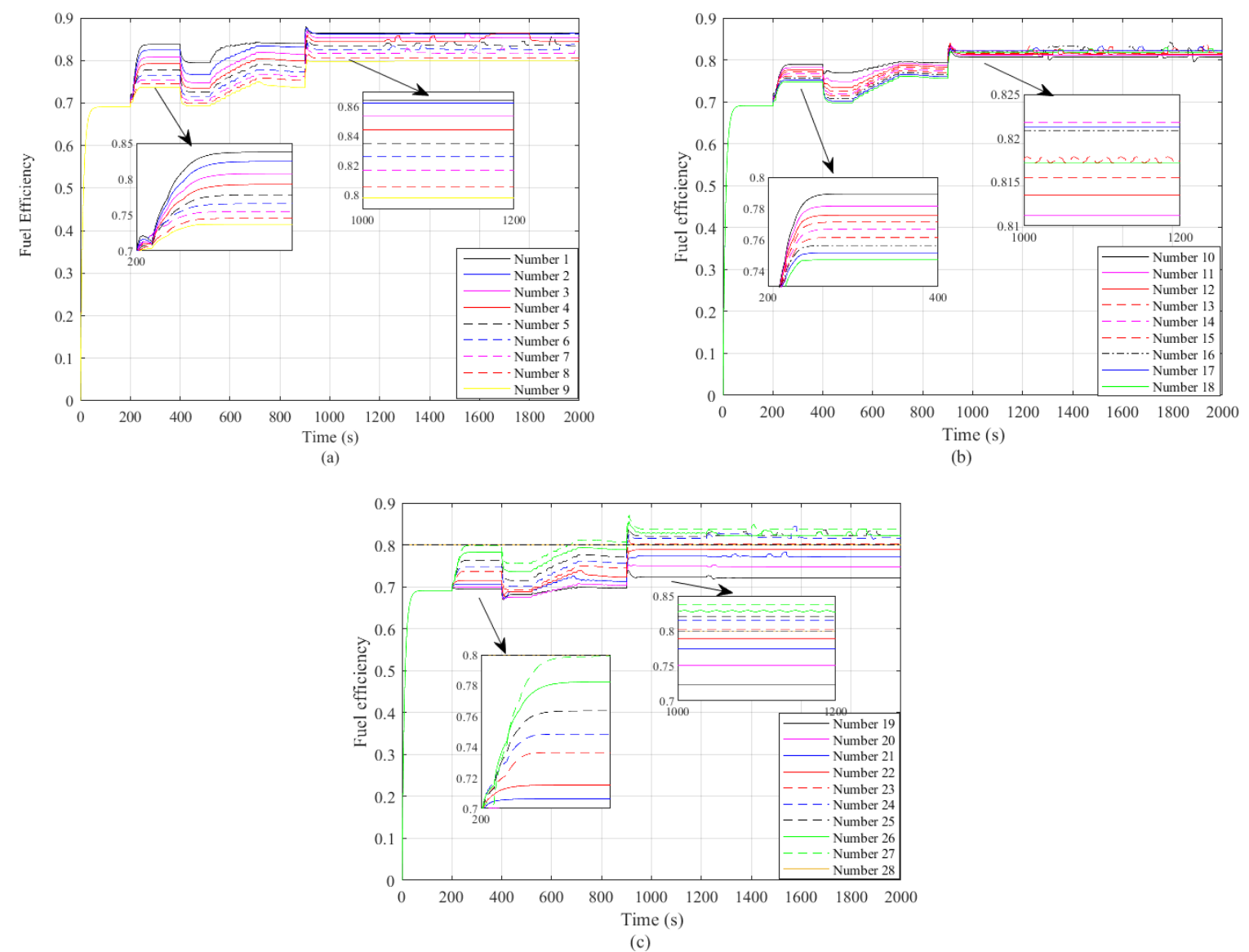

Fig. 8. Fuel efficiency curves obtained by adaptive three-step model predictive control (Case I): (a) Number 1-9; (b) Number 10-18; (c) Number 19-28.

Table 1. Fuel efficiencies obtained by adaptive three-step model predictive control (Case I)

\begin{tabular}{lllcccc}
\hline Number & $\begin{array}{l}\text { Tracking } \\
\text { controller }\end{array}$ & $\begin{array}{l}\text { Constraint } \\
\text { guaranteed? }\end{array}$ & $\begin{array}{l}\text { Weight of the first } \\
\text { controller }\end{array}$ & $\begin{array}{l}\text { Weight of the second } \\
\text { controller }\end{array}$ & $\begin{array}{l}\text { Weight of the third } \\
\text { controller }\end{array}$ & Fuel efficiency (\%) \\
\hline 1 & \multirow{2}{*}{ AMMPC-III } & Yes & 0.90 & 0.05 & 0.05 & 86.5 \\
2 & Yes & 0.80 & 0.10 & 0.10 & 86.0 \\
\hline
\end{tabular}




\begin{tabular}{|c|c|c|c|c|c|c|}
\hline 3 & AMMPC-III & Yes & 0.70 & 0.15 & 0.15 & 85.3 \\
\hline 4 & AMMPC-III & Yes & 0.60 & 0.20 & 0.20 & 84.4 \\
\hline 5 & AMMPC-III & Yes & 0.50 & 0.25 & 0.25 & 83.5 \\
\hline 6 & AMMPC-III & Yes & 0.40 & 0.30 & 0.30 & 82.6 \\
\hline 7 & AMMPC-III & Yes & 0.30 & 0.35 & 0.35 & 81.6 \\
\hline 8 & AMMPC-III & Yes & 0.20 & 0.40 & 0.40 & 80.5 \\
\hline 9 & AMMPC-III & Yes & 0.10 & 0.45 & 0.45 & 79.8 \\
\hline 10 & AMMPC-III & Yes & 0.05 & 0.90 & 0.05 & 80.0 \\
\hline 11 & AMMPC-III & Yes & 0.10 & 0.80 & 0.10 & 81.0 \\
\hline 12 & AMMPC-III & Yes & 0.15 & 0.70 & 0.15 & 81.3 \\
\hline 13 & AMMPC-III & Yes & 0.20 & 0.60 & 0.20 & 81.7 \\
\hline 14 & AMMPC-III & Yes & 0.25 & 0.50 & 0.25 & 82.1 \\
\hline 15 & AMMPC-III & Yes & 0.30 & 0.40 & 0.30 & 81.5 \\
\hline 16 & AMMPC-III & Yes & 0.35 & 0.30 & 0.35 & 82.0 \\
\hline 17 & AMMPC-III & Yes & 0.40 & 0.20 & 0.40 & 82.1 \\
\hline 18 & AMMPC-III & Yes & 0.45 & 0.10 & 0.10 & 81.8 \\
\hline 19 & AMMPC-III & Yes & 0.05 & 0.05 & 0.90 & 72.0 \\
\hline 20 & AMMPC-III & Yes & 0.10 & 0.10 & 0.80 & 75.0 \\
\hline 21 & AMMPC-III & Yes & 0.15 & 0.15 & 0.70 & 77.1 \\
\hline 22 & AMMPC-III & Yes & 0.20 & 0.20 & 0.60 & 78.8 \\
\hline 23 & AMMPC-III & Yes & 0.25 & 0.25 & 0.50 & 80.1 \\
\hline 24 & AMMPC-III & Yes & 0.30 & 0.30 & 0.40 & 81.5 \\
\hline 25 & AMMPC-III & Yes & 0.35 & 0.35 & 0.30 & 82.0 \\
\hline 26 & AMMPC-III & Yes & 0.40 & 0.40 & 0.20 & 82.5 \\
\hline 27 & AMMPC-III & Yes & 0.45 & 0.45 & 0.10 & 83.7 \\
\hline 28 & AMMPC-III & Yes & 1.00 & 0.00 & 0.00 & 80.0 \\
\hline & AMMPC-III & & & & & \\
\hline
\end{tabular}

The optimal fuel efficiency of the AMMPC-III controller is that when the weight of the first controller is 0.9 and the weight of the second and third controllers are both 0.05 (Fig. 8 and Table 1). The fuel efficiencies of the TGSOFC obtained by the AMMPC-II with constraint and different weights of two predicted controllers under Case I are shown in Table 2 and Fig. 9.

Table2. Fuel efficiencies obtained by adaptive two-step model predictive control (Case I)

\begin{tabular}{llllll}
\hline Number & $\begin{array}{l}\text { Tracking } \\
\text { controller }\end{array}$ & $\begin{array}{l}\text { Constraint } \\
\text { guaranteed? }\end{array}$ & $\begin{array}{l}\text { Weight of the first } \\
\text { controller }\end{array}$ & $\begin{array}{l}\text { Weight of the second } \\
\text { controller }\end{array}$ & Fuel efficiency (\%) \\
\hline 29 & AMMPC-II & Yes & 0.90 & 0.10 & 86.4 \\
30 & AMMPC-II & Yes & 0.80 & 0.20 & 85.7 \\
31 & AMMPC-II & Yes & 0.70 & 0.30 & 85.1 \\
32 & AMMPC-II & Yes & 0.60 & 0.40 & 84.6 \\
33 & AMMPC-II & Yes & 0.50 & 0.50 & 82.9 \\
34 & AMMPC-II & Yes & 0.40 & 0.60 & 82.2 \\
35 & AMMPC-II & Yes & 0.30 & 0.70 & 81.2 \\
36 & AMMPC-II & Yes & 0.20 & 0.80 & 80.5 \\
37 & AMMPC-II & Yes & 0.10 & 0.90 & 80.0 \\
38 & MPC & Yes & 1.00 & 0.00 & 80.0 \\
39 & PID & No & 0.00 & & \\
\hline
\end{tabular}

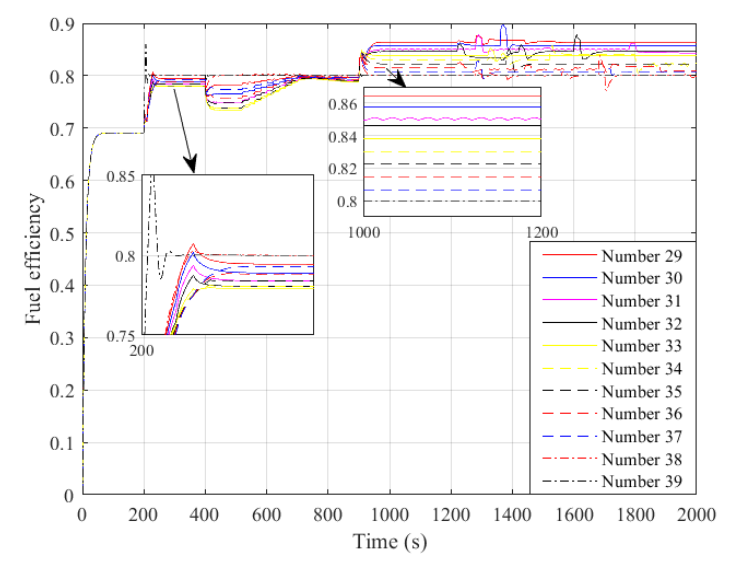

Fig. 9. Fuel efficiency curves obtained by adaptive two-step model predictive control (Case I) As shown in Table 2 and Fig. 9, the optimal control effect of the AMMPC-II controller is that when the weight of the first controller is 0.9 and the weight of the second controller is 0.1 , the fuel efficiency of the 
TGSOFC is the best in steady-state and transient process. The AMMPC-II algorithm can improve the fuel efficiency of the TGSOFC to $86.4 \%$, and the fuel efficiency based on the MPC controller is $80.0 \%$.

This paper compares the optimal weight controller of the AMMPC-III control algorithm with the optimal weight controller of the AMMPC-II control algorithm. The output power curves of the TGSOFCs with the proposed AMMPC-III and three compared methods (AMMPC-II, MPC, PID) are shown in Fig. 10. The TGSOFCs with AMMPC-III controller obtain higher fuel efficiency.

With the simple structure of the PID, the thermal characteristics of the resistance considered have little influence on the output power. With a complex control system of the MPC tracking controller, the internal resistance of TGSOFCs is increased; thus, the output powers of the MPC and AMMPCs are lower than that of the PID. Fig. 10 shows that (i) with the increasing internal resistance consumption, the AMMPC can provide the output power at a stable constant; (ii) the AMMPC-III (86.5\%) achieves higher control performance than the AMMPC-II (86.4\%).

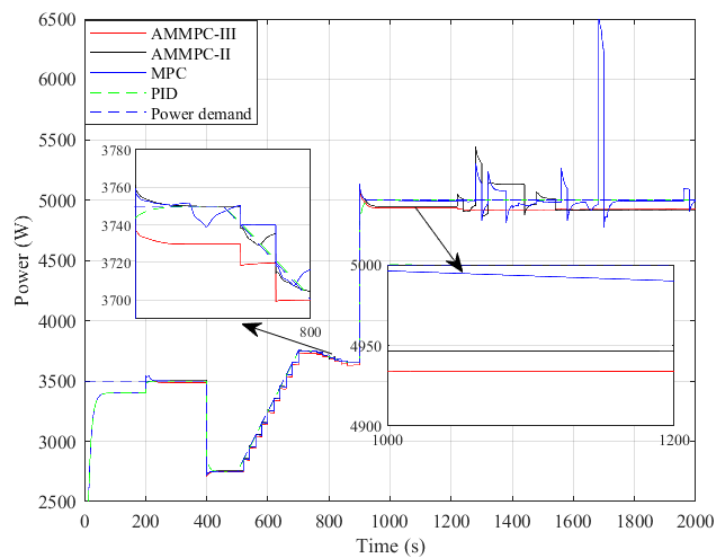

Fig. 10. Output power of tubular grid-connected solid oxide fuel cells under Case I

Fig. 11 presents the fuel efficiency curves of four compared control methods. The final fuel efficiency of both PID and MPC is $80.0 \%$. Fig. 11 shows that both AMMPC-III and AMMPC-II can positively improve the fuel efficiency larger than $86 \%$. Besides, the proposed AMMPC-III can obtain higher tracking performance than AMMPC-II, MPC, and PID.

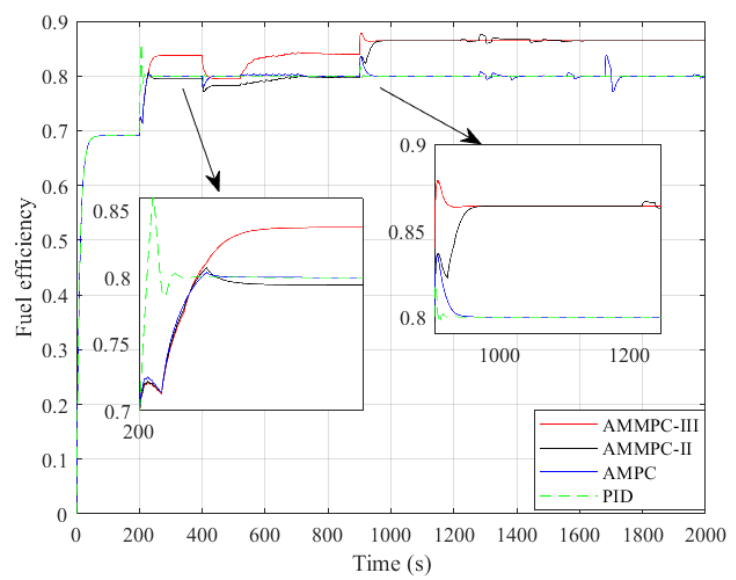

Fig. 11. Fuel efficiency of tubular grid-connected solid oxide fuel cells obtained by compared methods under Case I

The output voltage and current curves of TGSOFCs obtained by four compared methods are shown in Fig. 12. 


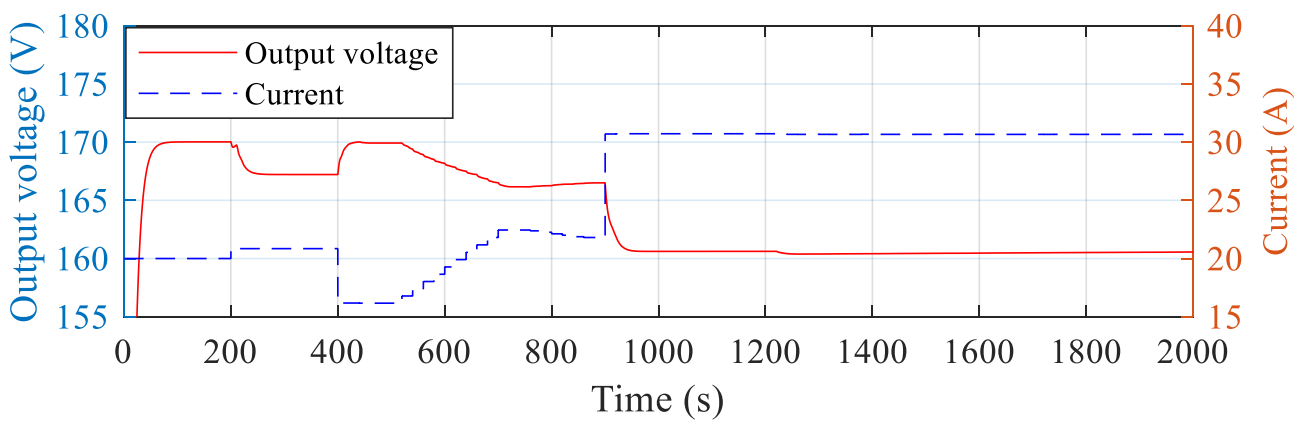

(a)

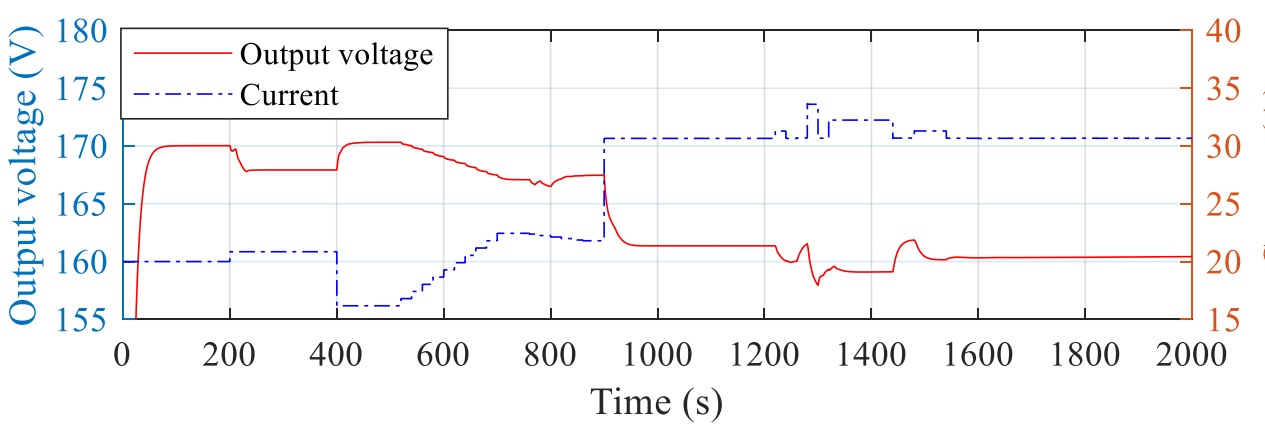

(b)

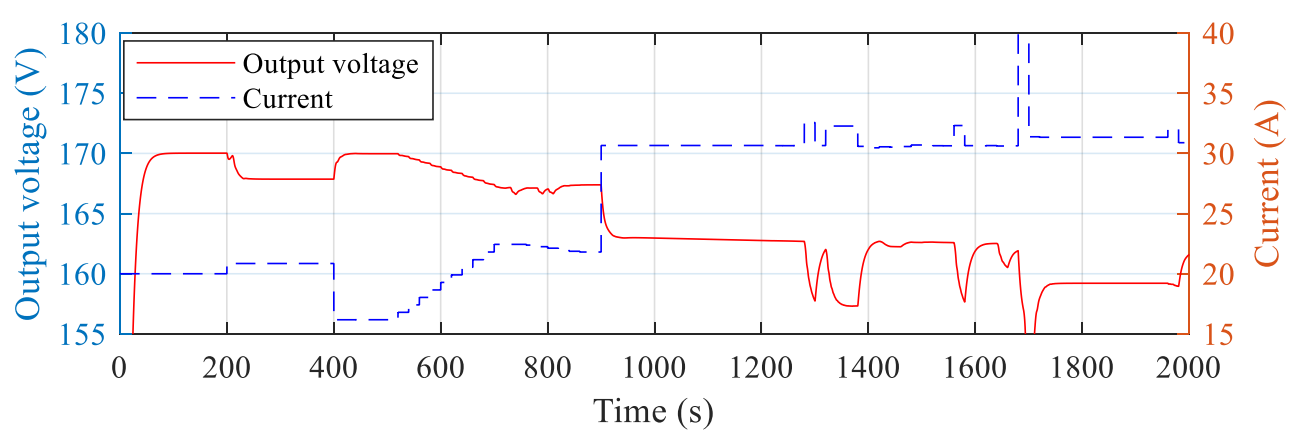

(c)

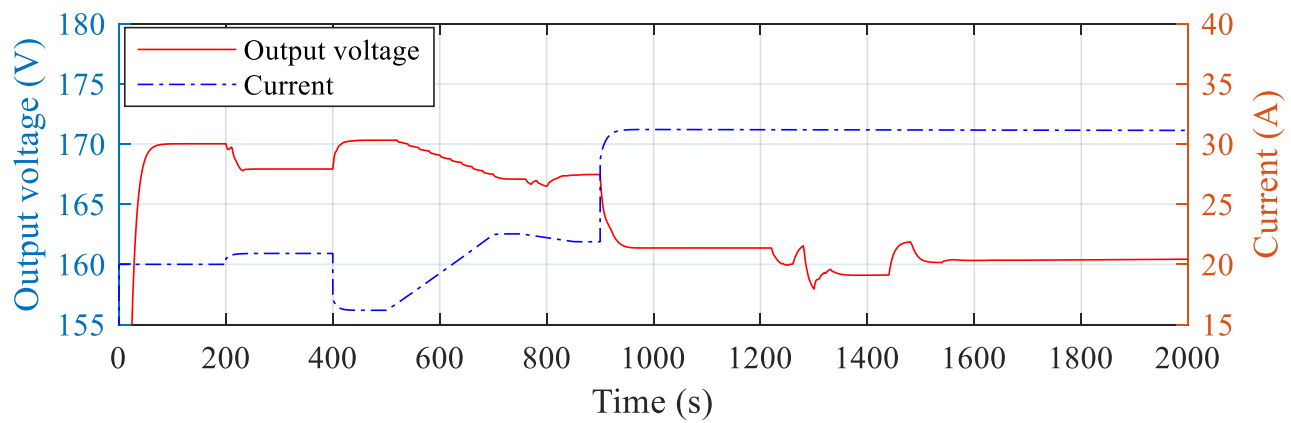

(d)

Fig. 12. Output voltage and current curves obtained by four compared controllers (Case I): (a) adaptive threestep proposed method; (b) adaptive two-step proposed method; (c) model predictive control; (d) proportionalintegral-derivative. 
Fig. 13 shows the inlet fuel flow and airflow curves of the TGSOFCs obtained by four compared methods.

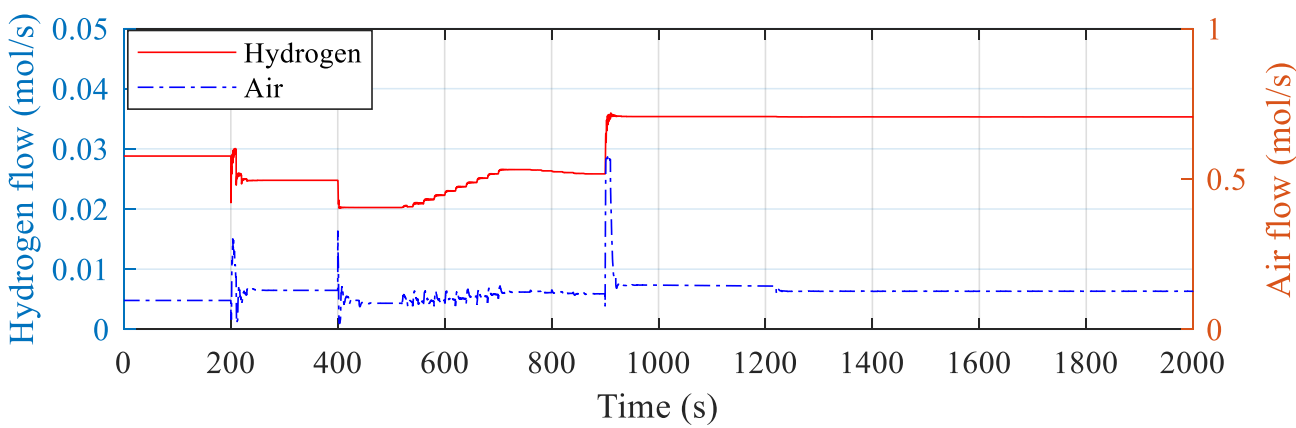

(a)

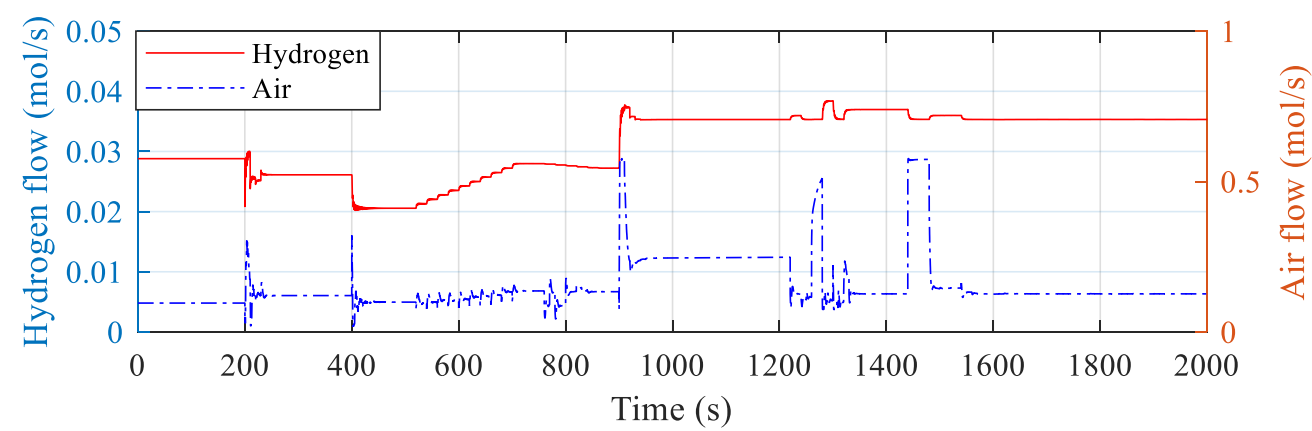

(b)

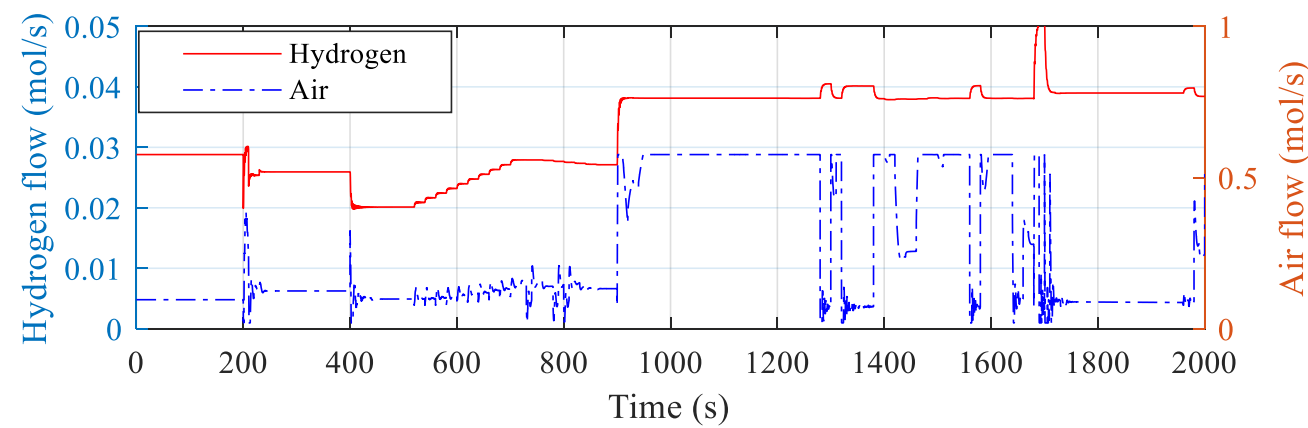

(c)

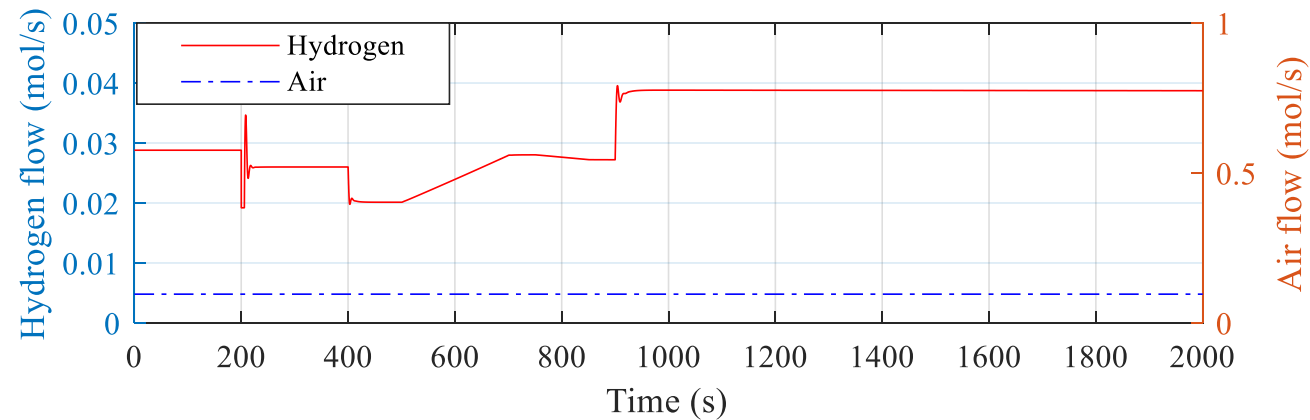

(d)

Fig. 13. Manipulated inputs obtained by compared controllers (Case I): (a) adaptive three-step proposed method; (b) adaptive two-step proposed method; (c) model predictive control; (d) proportional-integralderivative.

The control performances obtained by four compared methods under Case I are given in Table 3, which shows that the AMMPC can obtain the highest control performance than other compared methods. 
Table 3. Control performances obtained by four compared methods under Case I

\begin{tabular}{lllll}
\hline Tracking controller & Constraint guaranteed? & Stability & Tracking performance & Fuel efficiency(\%) \\
\hline AMMPC-III & Yes & Best & Best & 86.5 \\
AMMPC-II & Yes & Medium & Medium & 86.4 \\
MPC & Yes & Medium & Medium & 80.0 \\
PID & No & Worst & Worst & 80.0 \\
\hline
\end{tabular}

\subsection{Case of complex power demand (Case II)}

More complex power demand is designed Case II. In this case, the output power curves of the TGSOFCs obtained by compared methods are shown in Fig. 14. The fuel efficiency curves of four compared control methods under the complex power demand are presented in Fig. 15.

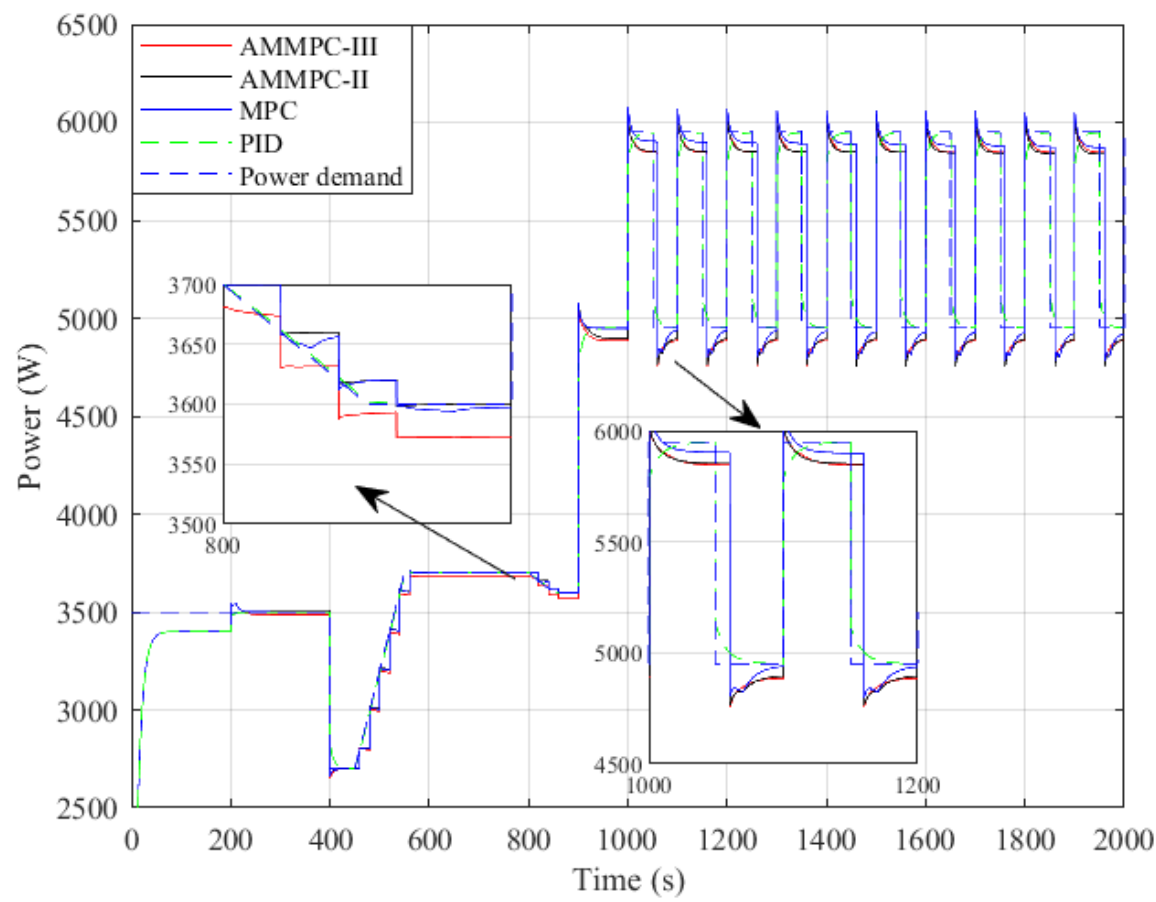

Fig. 14. Output power of tubular grid-connected solid oxide fuel cells under Case II

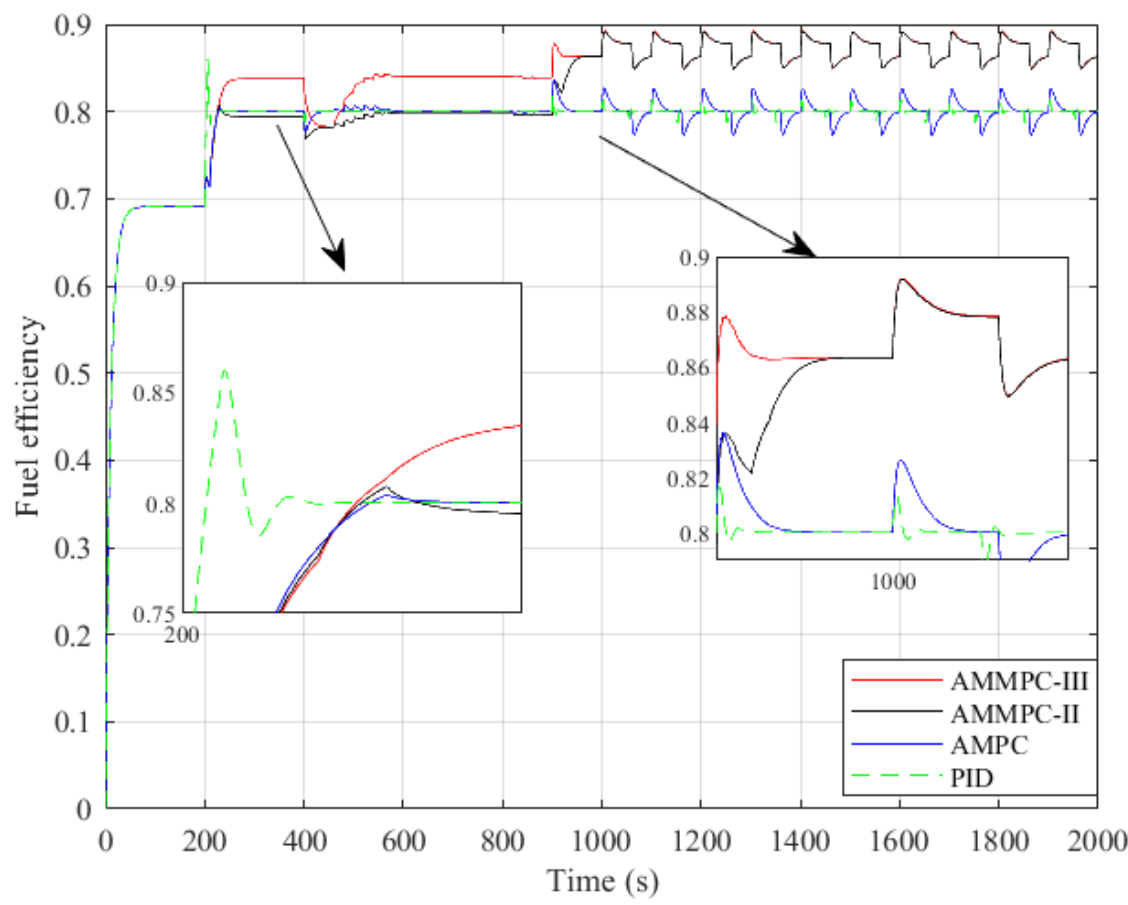

Fig. 15. Fuel efficiency of tubular grid-connected solid oxide fuel cells under Case II 
The output voltage and current curves of four compared control methods under the complex power demand are given in Fig. 16.

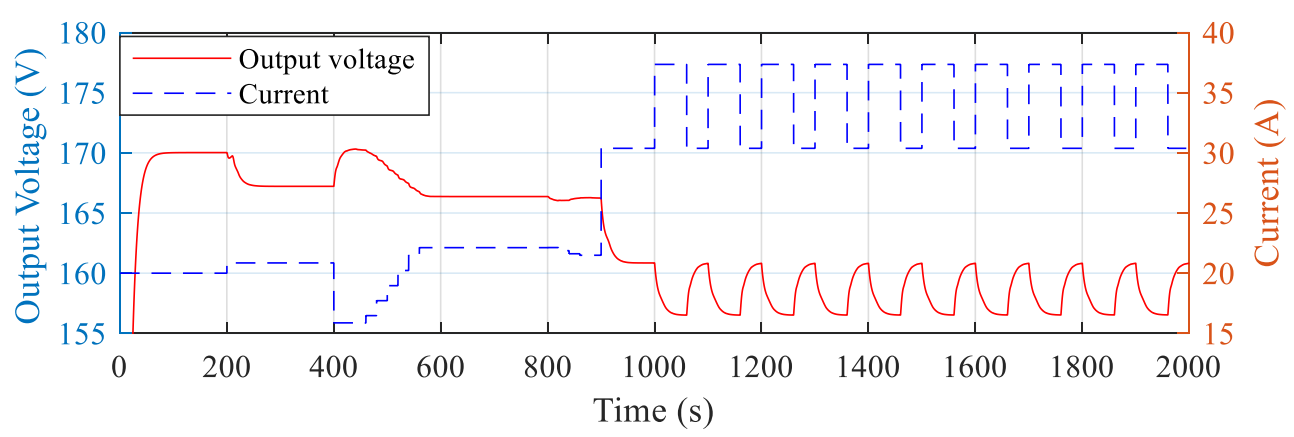

(a)

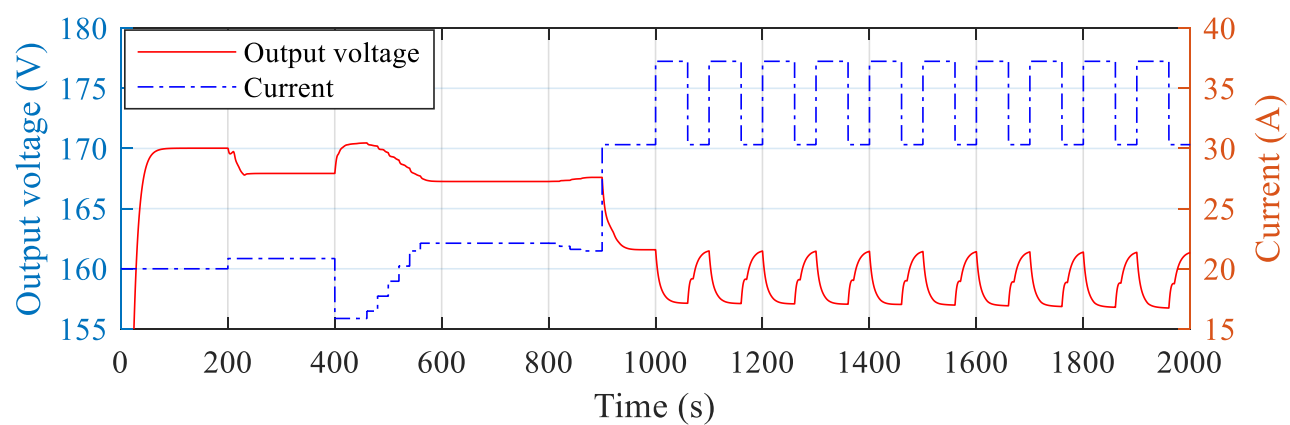

(b)

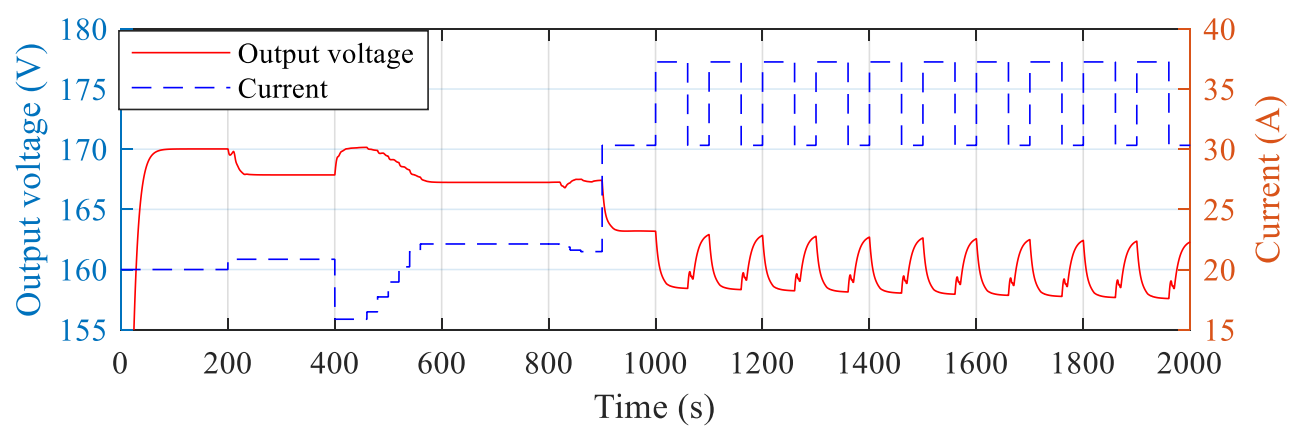

(c)

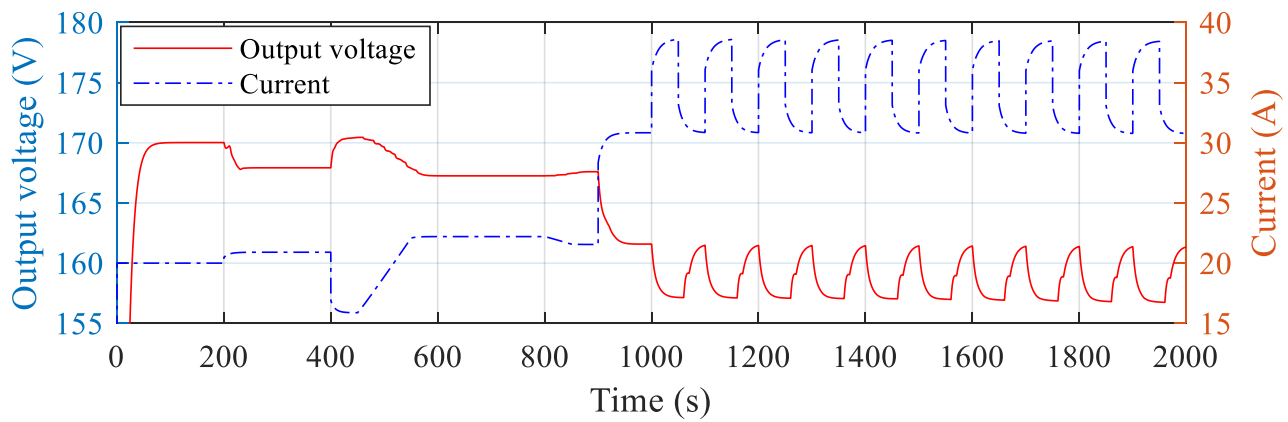

(d)

Fig.16. Output voltage and current obtained by compared controllers (Case II): (a) adaptive three-step proposed method; (b) adaptive two-step proposed method; (c) model predictive control; (d) proportionalintegral-derivative. 
Fig. 17 shows the inlet fuel flow and airflow curves of the TGSOFCs obtained by four compared methods.

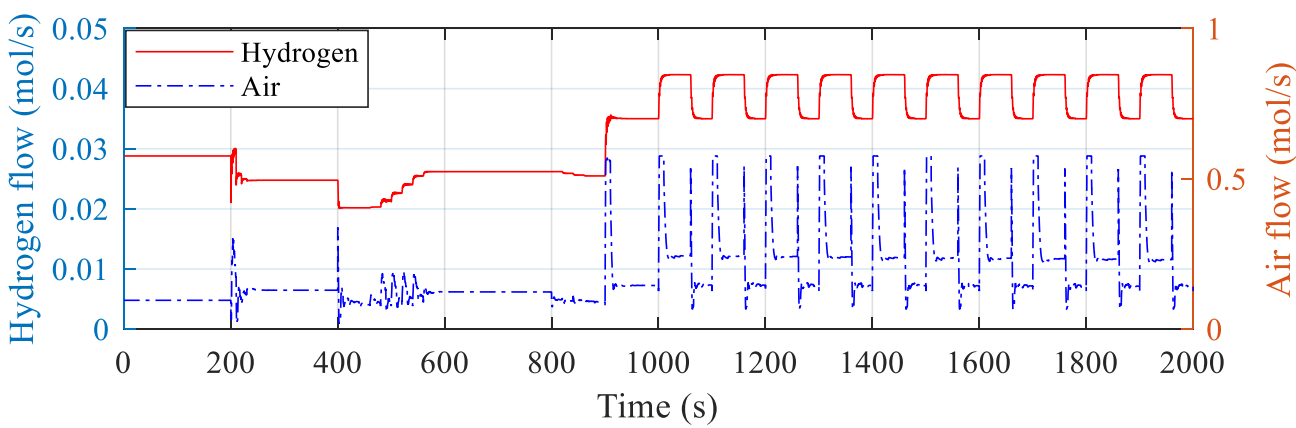

(a)

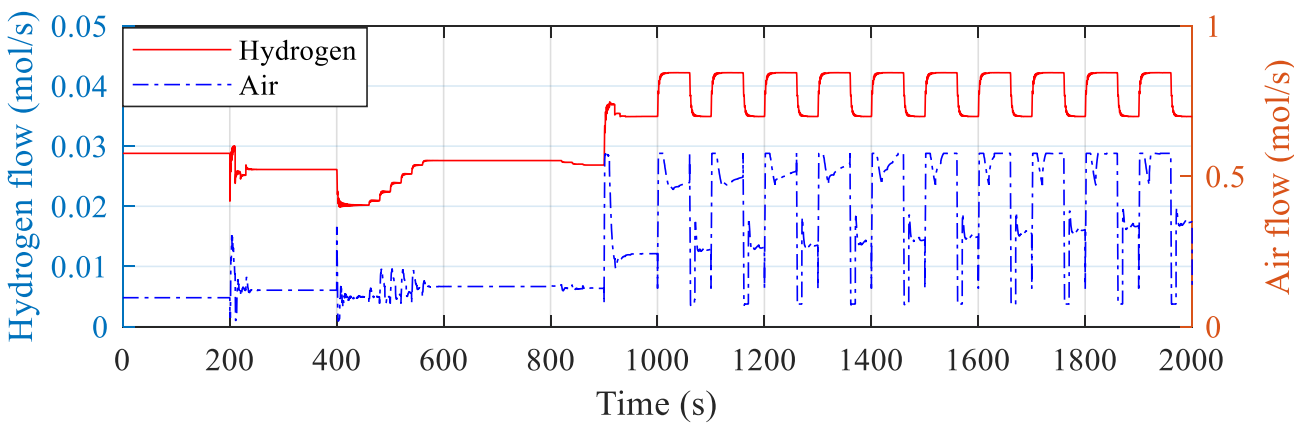

(b)

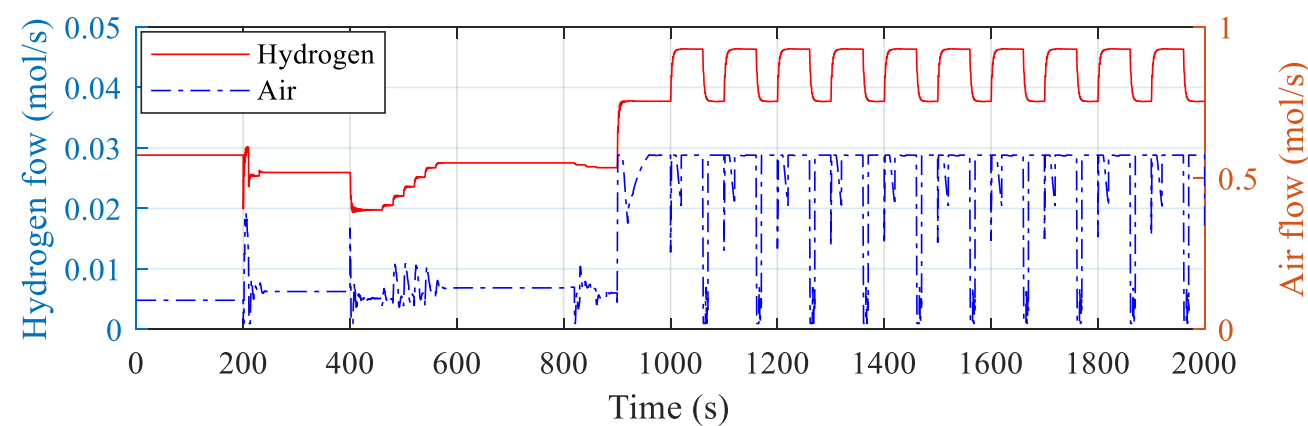

(c)

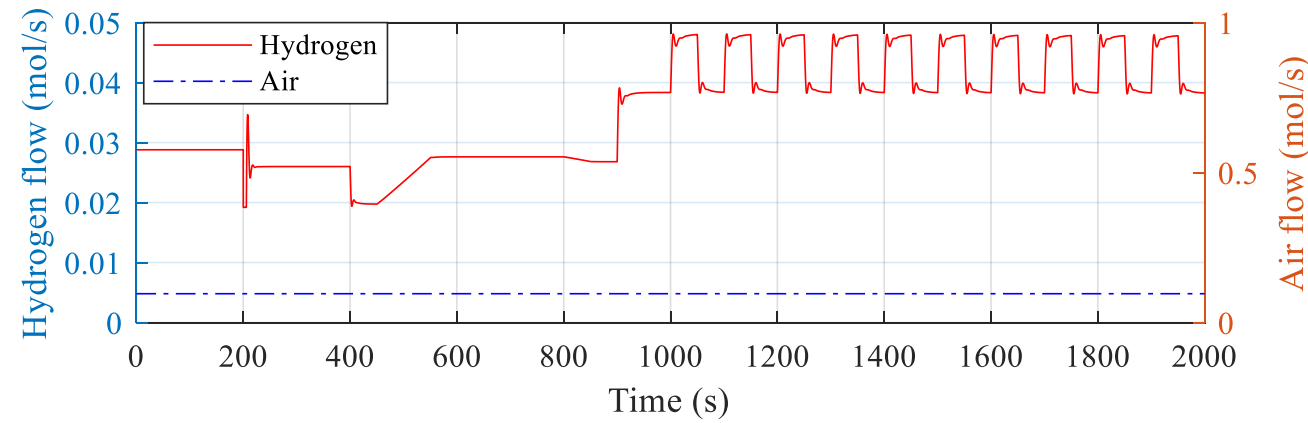

(d)

Fig. 17. Manipulated inputs obtained by compared controllers (Case II): (a) adaptive three-step model predictive control; (b) adaptive two-step model predictive control; (c) model predictive control; (d) proportional-integral-derivative.

Fig. 14 to Fig. 17 show that: (i) the AMMPC can obtain higher fuel efficiency of the TGSOFC than the PID and the MPC under complex power demand; (ii) the voltage regulation of power systems with TGSOFCs can be solved by the AMMPC; (iii) with more next steps are predicted, the AMMPC with three-step can obtain 
higher fuel efficiency during the changes of power demand than the AMMPC with two-step (Fig. 14 and Fig. 15); (iv) with more air is used by the TGSOFC, lesser hydrogen is needed for the TGSOFC; thus, both AMMPC and MPC need lesser cost and obtain higher fuel efficiency (Fig. 17).

After numerous testing: (i) the AMMPC with four steps has lower higher fuel efficiency than the AMMPC-III and AMMPC-II; (ii) the AMMPC-II and AMMPC-III with the weight of 0.9 of the first steps controller can obtain higher fuel efficiency than the AMMPC with other weights. The possible reason is that: the control system of the TGSOFC is a real-time short-term time-scale control system. Therefore, more steps (larger than three) could not be needed for the AMMPC-based TGSOFC. For a long-term time-scale control system, (i) the steps of the AMMPC should be configured as one of the hyperparameters; (ii) the number of the steps of the AMMPC for a long-term time-scale control system can be started from two.

\section{Conclusions}

This paper presents an AMMPC, which contains adaptive control and multistep MPC. The proposed AMMPC can predict the next systemic states with more accuracy than the MPC. Two case studies (i.e., simple and complex power demand cases) under power systems with TGSOFCs show that: the AMMPC can achieve the optimal value of current, can reduce the power loss caused by internal resistance, and can increase the fuel efficiency of TGSOFCs. The significant features of the AMMPC can be summarized as follows:

(1) The AMMPC contains the adaptive control and the multistep model predictive control, updating the control strategy online. The adaptive control of the AMMPC can adjust automatically according to system operation with the optimal control conditions. The multistep model predictive control can predict systemic state more accuracy with more steps is introduced into the AMMPC.

(2) The AMMPC can obtain higher fuel efficiency (86\%) than the MPC (80\%) and the PID (80\%) for TGSOFCs. The AMMPC-III that contains three steps can obtain higher fuel efficiency than the AMMPCII that contains two steps, which can obtain higher fuel efficiency than the MPC that contains only one step.

(3) The AMMPC can provide a dynamic control strategy for complex nonlinear systems with dynamic characteristics. More next steps information can be applied to a control algorithm.

In the future works, (i) the regulation economic performance of the TGSOFCs could be considered; (ii) the stability of the TGSOFCs under the influence of disturbance could be increased; (iii) the AMMPC could be extended to islanding microgrids; (iv) the AMMPC could be applied to other types fuel cells that can improve the systemic stability and fuel efficiency; (v) TGSOFCs could be utilized to balance active power and reduce frequency deviation of smart grids; (vi) expandable steps strategy could be designed to automatically determine the number of steps and the weights of multiple steps.

\section{Appendix. Nomenclature}

\section{Variables}

\section{$A$ : Reaction area}

$A_{\text {air supply tube, } H_{\text {outer }}}:$ Reaction area of air supply tube of the TGSOFC

$A_{C_{\text {cell }}, H_{\text {iner }}}:$ Inner reaction area of the TGSOFC 
$a_{\text {electrolyte }}$ : Constants of electrolyte resistances of the TGSOFC

$a_{C_{\text {intercomection }}}:$ Material resistances of interconnection between multiple TGSOFCs

$a, b$ : Resistance constants

$b_{\text {electrolyte }}$ : Constants of electrolyte resistances of the TGSOFC

$C$ : Control horizon of model predictive control

$C_{a i r}$ : Specific heat capacity of air during the chemical reaction process of the TGSOFC

$C_{\mathrm{H}_{2}}$; Specific heat capacity of hydrogen during the chemical reaction process of the TGSOFC

$C_{\mathrm{H}_{2} \mathrm{O}}$ : Specific heat capacity of steam during the chemical reaction process of the TGSOFC

$C_{\text {cell }}:$ Conditions in cell

$C_{\text {channel }}:$ Conditions in channels

$C_{\text {in }} / C_{\text {out }}$ : Condition of inlet/outlet

$C_{\text {connection }}$ : Connection between cells

$d$ : Disturbance

$\delta$ : Length of the electrode

$\delta_{C_{\text {interconnection }}}:$ Thickness of interconnection between multiple TGSOFCs

$\delta_{\text {electrolyte }}:$ Thickness of the electrolyte of the TGSOFC

$\Delta \mathrm{H}$ : Entropy of hydrogen in the chemical reactions of the TGSOFC

$\Delta x_{\phi, t+\lambda}$ : Increment of the variable $\phi$ of the $\lambda$ iteration in the control horizon

$\Delta x_{\phi}:$ Increment of the manipulated variable $\phi$

$E$ : Open-loop electric potential

$E_{C_{\text {cell }}, 0}:$ Reference electric potential of the TGSOFC

$\varepsilon_{i}$ : Weighted coefficient of each adaptive multistep model predictive control

$\xi_{0}, \xi_{1}$ : Activation reduction factor

$\xi$ : Constant greater than zero

$F$ : Faraday constant

$\phi$ : Controlled variable

$\psi:$ Controlled variable

$h$ : Convective heat-transfer coefficient

$h_{C_{\text {cell }}}:$ Convective heat-transfer constant of the chemical reaction of the TGSOFC

$h_{\psi, t}$ : Difference between the measured values and predicted values

$H$ : Enthalpy

$H_{\text {flow }}:$ Heat carried off by the flow 
$H_{\text {inner }} / H_{\text {outer }}$ : Heat transfer to inner /outer channel

$\mathrm{H}_{2}$ : Hydrogen

$\mathrm{H}_{2} \mathrm{O}$ : Water

$\rho$ : Adaptation rate of the controlled objective

I: Current

$\eta$ : Fuel efficiency

$\eta_{\text {upper }}:$ Upper bound of the fuel efficiency

$k$ : Empirical parameter

$\varepsilon$ : Weight of controller

$\varepsilon_{\text {air supply tube }}^{*}$ : Emissivity constant of a chemical reaction of the TGSOFC

$M$ : Controlled variables of model predictive control

$M_{\text {anode }}$ : Mass of anode

$M_{\text {anode }}^{C_{\text {in }}}:$ Total mass of gas entering anode

$M_{\text {anode }}^{C_{\text {out }}}$ : Total mass of gas leaving anode

$M_{\mathrm{H}_{2}}^{C_{\text {in }}}$ : Mass of hydrogen in the channel inlet

$M_{\mathrm{H}_{2}}^{C_{\text {out }}}$ : Mass of hydrogen in the channel outlet

$M_{\mathrm{O}_{2}}^{C_{\text {in }}}$ : Mass of oxygen in the channel inlet

$M_{\mathrm{O}_{2}}^{C_{\text {out }}}$ : Mass of oxygen in the channel outlet

$M_{\mathrm{H}_{2} \mathrm{O}}^{C_{\text {in }}}$ : Mass of steam in the channel inlet

$M_{\mathrm{H}_{2} \mathrm{O}}^{C_{\text {out }}}$ : Mass of steam in the channel outlet

$M_{\text {Molar mass,air }}$ : Molar mass of air during the chemical reaction process of the TGSOFC

$M_{\text {Molar mass, } \mathrm{H}_{2}}:$ Molar mass of hydrogen during the chemical reaction process of the TGSOFC

$M_{\text {Molar mass }, \mathrm{H}_{2} \mathrm{O}}$ : Molar mass of steam during the chemical reaction process of the TGSOFC

$N$ : Manipulated variables of model predictive control

$N_{\text {step }}$ : Number of steps of the adaptive multistep model predictive control

$n_{H_{2} \text {,consumed }}$ : Moles of hydrogen consumed by the chemical reactions of the TGSOFC

$\lambda:$ Number of iterations

$\mathrm{O}_{2}$ : Oxygen

$P$ : Prediction horizon of model predictive control

$p$ : Pressure

$p_{\text {anode }}^{C_{\text {in }}}$ : Total pressure of gas entering anode

$p_{\text {anode }}^{C_{\text {out }}}$ : Total pressure of gas living anode 
$p_{\text {cathode }}^{C_{\text {in }}}:$ Total pressure of gas entering anode

$p_{\text {cathode }}^{C_{\text {ot }}}:$ Total pressure of gas living anode

$p_{\mathrm{H}_{2}}^{*}$ : Effective value of the pressure of hydrogen during the chemical reaction process of the TGSOFC

$p_{\mathrm{O}_{2}}^{*}$ : Effective value of the pressure of oxygen during the chemical reaction process of the TGSOFC

$p_{\mathrm{H}_{2} \mathrm{O}}^{*}$ : Effective value of the pressure of steam during the chemical reaction process of the TGSOFC

$p_{\mathrm{H}_{2}}^{C_{\text {chanel }}}$ : Pressure of hydrogen of the air supply channel

$p_{\mathrm{H}_{2}}^{C_{\text {in }}}$ : Inlet pressure of hydrogen of the air supply channel

$p_{\mathrm{H}_{2}}^{C_{\text {out }}}$ : Outlet pressure of hydrogen of the air supply channel

$p_{\mathrm{O}_{2}}^{C_{\text {chanel }}}$ : Pressure of oxygen of the channel

$p_{\mathrm{O}_{2}}^{C_{\text {in }}}$ : Inlet pressure of oxygen in the channel

$p_{\mathrm{O}_{2}}^{C_{\text {out }}}$ : Outlet pressure of oxygen of the channel

$p_{\mathrm{H}_{2} \mathrm{O}}^{C_{\text {chal }}}$ : Pressure of steam of the channel

$p_{\mathrm{H}_{2} \mathrm{O}}^{C_{\text {in }}}$ : Inlet pressure of steam of the channel

$p_{\mathrm{H}_{2} \mathrm{O}}^{C_{\text {out }}}$ : Outlet pressure of steam of the channel

$Q$ : Energy transferred

$Q_{\text {chemical }}$ : Heat generated by the chemical reactions of the TGSOFC

$Q_{\text {radiation }}:$ Heat radiation consumed of the TGSOFC

$Q_{\text {cell,annulus,convection }}$ : Heat loss caused by the conversion between the air supply tube and annulus of the TGSOFC

$Q_{\text {cell,fuel,convection }}$ : Heat loss caused by fuel transfer between the annulus and the supply tube of the TGSOFC

$Q_{\text {fuel }, H_{\text {flow }}}:$ Heat transmission of fuel combustion of the TGSOFC

$Q_{\text {air,annulus }, H_{\text {flow }}}:$ Heat carried by air at the annulus of the TGSOFC

$Q_{\text {air supply tube,annulus,convection }}$ : Heat transfer between the annulus and the air supply tube of the TGSOFC

$Q_{\text {air supply tube, } H_{\text {iner }}, \text { convection }}$ : Heat convection at the inner of the air supply tube of the TGSOFC

$Q_{\text {air supply tube,annulus,convection }}$ : Heat convection at the annulus of the air supply tube of the TGSOFC

$Q_{\text {air,air supply tube, } H_{\text {flow }}}$ : Heat of air flowing at the air supply tube of the TGSOFC

$Q_{\text {air supply tube,inside,convection }}$ : Heat convection of the air supply tube of the TGSOFC

$q_{\text {Projection }}:$ Projection operator of controlled systems

$R$ : Resistance

$R_{\text {activation, }, C_{\text {cell }}}:$ Activation resistance of the TGSOFC 
$q$ : Adaptive gain

$T$ : Temperature

$T_{\text {air supply tube }}$ : Air supply tube temperature during the chemical reaction process of the TGSOFC

$T_{\text {air,air supply tube }}$ : Air temperature of the channel of the TGSOFC

$T_{\text {air, } \mathrm{C}_{\text {in }}}:$ Air temperature at the inlet of the channel of the TGSOFC

$T_{\text {air }, C_{\text {cell }}}:$ Air temperature of the TGSOFC

$T_{\text {air,air supply tube,annulus }}$ : Air temperature at the annulus of the air supply tube of the TGSOFC

$T_{\text {air,annulus }}:$ Air temperature of the annulus of the TGSOFC

$T_{\text {air }, C_{\text {out }}}:$ Air temperature at the outlet of the channel of the TGSOFC

$T_{C_{\text {cell }}}:$ Temperature of the TGSOFC

$T_{C_{\text {cell }}}^{4}:$ Fourth power of temperature in reaction cell of the TGSOFC

$T_{C_{\text {air supply tube }}}^{4}$ : Fourth power of temperature in air supply tube of the TGSOFC

$T_{\text {fuel }}:$ Fuel temperature of the TGSOFC

$T_{\text {fuel, } C_{\text {in }}}:$ Fuel temperature at the inlet of the channel of the TGSOFC

$T_{\text {fuel, } C_{\text {out }}}:$ Fuel temperature at the outlet of the channel of the TGSOFC

$t$ : Step time

$\sigma$ : Stefan Boltzmann constant

$V$ : Voltage

$V_{\text {activation, } C_{\text {cell }}}$ : Voltage drop caused by the activation reactant of the TGSOFC

$V_{\text {concentration, } C_{\text {cell }}}:$ Voltage drop caused by the concentration decreasing after the chemical reaction of the TGSOFC

$V_{C_{\text {out }}}:$ Output voltage of the TGSOFC

$V_{\text {ohmic, } C_{\text {cell }}}:$ Voltage drop of ohmic resistance of the TGSOFC

$W$ : Weight proportion

$w_{\phi, \lambda}$ : Weight of the variable $\phi$ of the $\lambda$ iteration in the control horizon

$x$ : Manipulated variables

$x_{\phi}$ : Manipulated variable of the $\phi$

$x_{\phi, \min }:$ Lower bound of the variable $\phi$

$x_{\phi, \max }:$ Upper bound of the variable $\phi$

$Y\left(k T_{\text {AMMPC }}\right)$ : Predicted output of the adaptive multistep model predictive control

$Y\left(k T_{\mathrm{MPC}}\right)$ : Output predicted by the model predictive control

$y$ : Controlled variables 
$y_{\psi, t}$ : Measured value of the controlled variable $\psi$

$y_{\psi, t}^{m}:$ Feedforward function in the $\psi$ th iteration

$y_{\psi, \min }$ : Lower bound of the variable $\psi$

$y_{\psi, \max }:$ Upper bound of the variable $\psi$

$y_{\psi, t+\theta}^{s}$ : Setpoint value of the controlled variable $\psi$

$y^{m}{ }_{\psi, t+\theta}$ : Predicted value of the controlled variable $\psi$

$z$ : Number of participating electrons

\section{Abbreviations}

AC: Alternating current

AMMPC: Adaptive multistep model predictive control

AMMPC-II: Two-step model predictive control

AMMPC-III: Three-step model predictive control

DC: Direct current

MPC: Model predictive control

PID: Proportional-integral-derivative

TGSOFC: Tubular grid-connected solid oxide fuel cell

VSI: Voltage source inverter

\section{Appendix 1}

$\mathrm{G}(s)=\left(\begin{array}{cc}\frac{28.51}{s+0.0834} & \frac{1.098}{s+0.08753} \\ \frac{-378}{s+0.09847} & \frac{1.539 e-6}{s+0.09847}\end{array}\right), \alpha=1 \mathrm{e}^{5}, C_{1}(s)=\frac{1}{s+1}, C_{2}(s)=\frac{0.4}{s+0.4}, Q=\left(\begin{array}{cc}0.5 & 0 \\ 0 & 10\end{array}\right)$,

$R=\left(\begin{array}{cc}100 & 0 \\ 0 & 100\end{array}\right), M=5, N=50, \quad L=\left(\begin{array}{cc}0.0329 & 0 \\ -0.0095 & 0 \\ 0 & -0.0058\end{array}\right), y_{\min }=\left(\begin{array}{c}0.5 \\ 0.72\end{array}\right), y_{\max }=\left(\begin{array}{c}1.5 \\ 0.88\end{array}\right)$,

$u_{\min }=\left(\begin{array}{c}1 e^{-4} \\ 1 e^{-4}\end{array}\right), u_{\max }=\left(\begin{array}{c}2.55 e^{-3} \\ 24.5 e^{-3}\end{array}\right), p_{\text {anode }}^{C_{\text {in }}}=p_{\text {canode }}^{C_{\text {in }}}=2 a t m, T_{\text {air }, C_{\text {inlet }}}=T_{\text {fuel, }, C_{\text {inlet }}}=973 \mathrm{~K}$

\section{Acknowledgments}

This work was supported by the National Natural Science Foundation of Guangxi Province under Grant. AD19245001 and 2020GXNSFBA159025.

\section{Author contributions}

All the authors contributed equally to this research paper.

\section{Declaration}

Conflict of interest: The authors declare that they have no conflict of interest. 
Human and animal ethical standards: This article does not contain any studies with human participants or animals performed by any of the authors.

\section{References}

[1] H. Haddadian, R. Noroozian. (2017). Multi-microgrids approach for design and operation of future distribution networks based on novel technical indices, Applied Energy 185(1), 650-663.

[2] Khan, M. J., \& Mathew, L. (2021). Artificial neural network-based maximum power point tracking controller for real-time hybrid renewable energy system. Soft Computing, 25(8), 6557-6575.

[3] Vanbuel, J., Ferrari, P., \& Janssens, E. (2020). Few-atom cluster model systems for a hydrogen economy. Advances in Physics: X, 5(1), 1754132.

[4] Collins, J. M., \& McLarty, D. (2020). All-electric commercial aviation with solid oxide fuel cell-gas turbine-battery hybrids. Applied Energy, 265, 114787.

[5] Al-Hamed, K. H. M., \& Dincer, I. (2020). A novel integrated solid-oxide fuel cell powering system for clean rail applications. Energy Conversion and Management, 205, 112327.

[6] Corigliano, O., \& Fragiacomo, P. (2020). Extensive analysis of SOFC fed by direct syngas at different anodic compositions by using two numerical approaches. Energy Conversion and Management, 209, 112664.

[7] Roushenas, R., Razmi, A. R., Soltani, M., Torabi, M., Dusseault, M. B., \& Nathwani, J. (2020). Thermoenvironmental analysis of a novel cogeneration system based on solid oxide fuel cell (SOFC) and compressed air energy storage (CAES) coupled with turbocharger. Applied Thermal Engineering, 181, 115978.

[8] Dötschel, T., Auer, E., Rauh, A., \& Aschemann, H. (2013). Thermal behavior of high-temperature fuel cells: Reliable parameter identification and interval-based sliding mode control. Soft Computing, 17(8), 1329-1343.

[9] Kim, Y. S., Lee, Y. D., \& Ahn, K. Y. (2020). System integration and proof-of-concept test results of SOFCengine hybrid power generation system. Applied Energy, 277, 115542.

[10] Nelson, J. R., \& Johnson, N. G. (2020). Model predictive control of microgrids for real-time ancillary service market participation. Applied Energy, 269, 114963.

[11] Garduno-Ramirez, R.; Lee, K.Y. (2001). Multiobjective optimal power plant operation scheduling. IEEE Transactions on Energy Conversation. 16, 115-122.

[12] Rosner, F., Rao, A., \& Samuelsen, S. (2020). Economics of cell design and thermal management in solid oxide fuel cells under SOFC-GT hybrid operating conditions. Energy Conversion and Management, 220, 112952.

[13] Radenahmad, N., Azad, A. T., Saghir, M., Taweekun, J., Bakar, M. S. A., Reza, M. S., \& Azad, A. K. (2020). A review on biomass derived syngas for SOFC based combined heat and power application. Renewable and Sustainable Energy Reviews, 119, 109560. 
[14] L. Yin, G. Turesson, P. Tunestål and R. Johansson. (2020). "Model predictive control of an advanced multiple cylinder engine with partially premixed combustion concept," IEEE/ASME Transactions on Mechatronics, 25(2), 804-814.

[15] Han, S., Sun, L., Shen, J., Pan, L., \& Lee, K. Y. (2018). Optimal load-tracking operation of grid-connected solid oxide fuel cells through set point scheduling and combined L1-MPC control. Energies, 11(4), 801.

[16] Boulkaibet, I., Belarbi, K., Bououden, S., Chadli, M., \& Marwala, T. (2018). An adaptive fuzzy predictive control of nonlinear processes based on Multi-Kernel least squares support vector regression. Applied Soft Computing, 73, 572-590.

[17] Hou, G., Gong, L., Yang, Z., \& Zhang, J. (2020). Multi-objective economic model predictive control for gas turbine system based on quantum simultaneous whale optimization algorithm. Energy Conversion and Management, 207, 112498.

[18] Wu, X. L., Xu, Y. W., Zhao, D. Q., Zhong, X. B., Li, D., Jiang, J. H., Deng, Z. H., Fu, X. W., \& Li, X. (2020). Extended-range electric vehicle-oriented thermoelectric surge control of a solid oxide fuel cell system. Applied Energy, 263, 114628.

[19] Priya, G. S., \& Sivakumar, P. (2019). Analysis of antlion optimizer-based ABT for automatic generation control of an interconnected power system. Soft Computing, 23(18), 8563-8577.

[20] Sahu, P. C., Prusty, R. C., \& Sahoo, B. K. (2020). Modified sine cosine algorithm-based fuzzy-aided PID controller for automatic generation control of multiarea power systems. Soft Computing, 24(17), 1291912936.

[21] Yang, B., Wang, J., Zhang, M., Shu, H., Yu, T., Zhang, X., Yao, W., Sun, L. (2020). A state-of-the-art survey of solid oxide fuel cell parameter identification: Modelling, methodology, and perspectives. Energy Conversion and Management, 213, 112856.

[22] Rosner, F., Rao, A., \& Samuelsen, S. (2020). Economics of cell design and thermal management in solid oxide fuel cells under SOFC-GT hybrid operating conditions. Energy Conversion and Management, 220, 112952.

[23] Qin, Y., Du, J., Lu, L., Gao, M., Haase, F., Li, J., \& Ouyang, M. (2020). A rapid lithium-ion battery heating method based on bidirectional pulsed current: heating effect and impact on battery life. Applied Energy, $280,115957$.

[24] Wang, C.; Nehrir, M.H. (2007). A physically based dynamic model for solid oxide fuel cells. IEEE Transactions on Energy Conversation, 22, 887-897.

[25] Emadi, M. A., Chitgar, N., Oyewunmi, O. A., \& Markides, C. N. (2020). Working-fluid selection and thermoeconomic optimisation of a combined cycle cogeneration dual-loop organic Rankine cycle (ORC) system for solid oxide fuel cell (SOFC) waste-heat recovery. Applied Energy, 261, 114384.

[26] Nazerifard, R., Khani, L., Mohammadpourfard, M., Mohammadi-Ivatloo, B., \& Akkurt, G. G. (2021). Design and thermodynamic analysis of a novel methanol, hydrogen, and power trigeneration system based on renewable energy and flue gas carbon dioxide. Energy Conversion and Management, 233, 113922. 
[27] Liu, J., Luo, W., Yang, X., \& Wu, L. (2016). Robust model-based fault diagnosis for PEM fuel cell airfeed system. IEEE Transactions on Industrial Electronics, 63(5), 3261-3270.

[28] Zhao, H., Zhao, Z., \& Wang, H. (2020). Thermodynamic performance study of the CLHG/SOFC combined cycle system with CO2 recovery. Energy Conversion and Management, 223, 113319.

[29] Zeng, Z., Qian, Y., Zhang, Y., Hao, C., Dan, D., \& Zhuge, W. (2020). A review of heat transfer and thermal management methods for temperature gradient reduction in solid oxide fuel cell (SOFC) stacks. Applied Energy, 280, 115899.

[30] Li, C., Jia, X., Zhou, Y., \& Li, X. (2020). A microgrids energy management model based on multi-agent system using adaptive weight and chaotic search particle swarm optimization considering demand response. Journal of Cleaner Production, 262, 121247.

[31] Brus, G., Raczkowski, P. F., Kishimoto, M., Iwai, H., \& Szmyd, J. S. (2020). A microstructure-oriented mathematical model of a direct internal reforming solid oxide fuel cell. Energy Conversion and Management, 213, 112826.

[32] He, H., Quan, S., Sun, F., \& Wang, Y. X. (2020). Model predictive control with lifetime constraints based energy management strategy for proton exchange membrane fuel cell hybrid power systems. IEEE Transactions on Industrial Electronics, 67(10), 9012-9023.

[33] Dai, L., Lu, Y., Xie, H., Sun, Z., \& Xia, Y. (2020). Robust tracking MPC with quadratic robustness constraint for mobile robots with incremental input constraints. IEEE Transactions on Industrial Electronics. 1-1(Early access).

[34] Wang, S., \& Na, J. (2020). Parameter estimation and adaptive control for servo mechanisms with friction compensation. IEEE Transactions on Industrial Informatics, 16(11), 6816-6825.

[35] Maiti, R., Sharma, K. D., Sarkar, G., \& Chandra, S. (2020). Modeling and control of delayed, nonlinear, uncertain, disturbed air heater employing fuzzy PDC-L1 adaptive scheme. IEEE Transactions on Industrial Electronics, 1-1(Early access). 